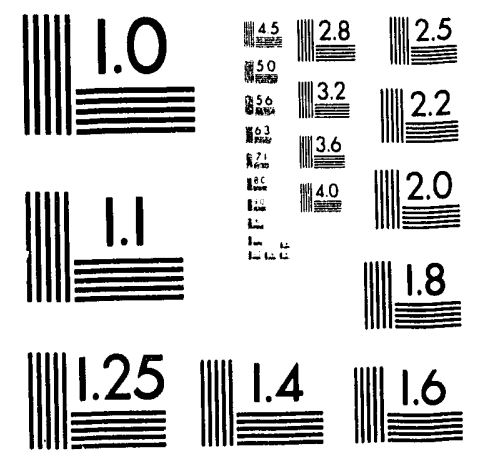



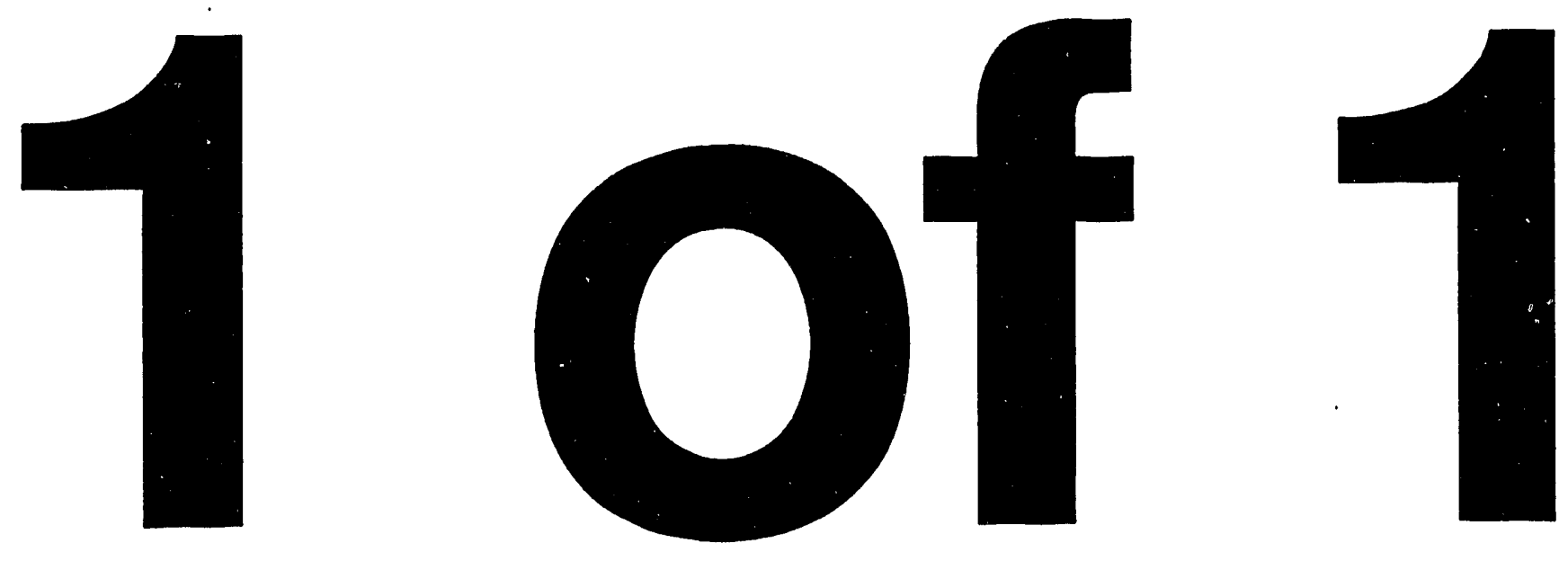
Future Radioactive

Liquid Waste Streams Study

Alfredo S. Rey 
EXECUTIVE SUMMARY

ABSTRACT .

I. INTRODUCTION

II. PROJECTED SCENARIOS . . . . . . . . . . . . . . 2

A. Scenarios . . . . . . . . . . . . . . . . . . . . . . . . . . . .

B. Observations . . . . . . . . . . . . . . . . . . . . . 5

III. POLICY AND REQUIREMENT DRIVERS . . . . . . . . . . . 6

A. Relevant Requirements . . . . . . . . . . . . . . . 6

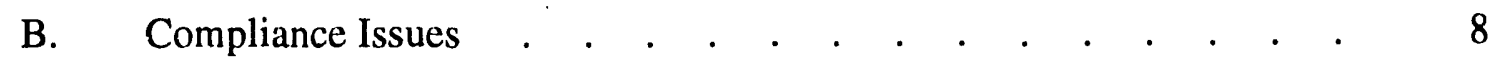

IV. SYSTEM INFORMATION AND PRESENT STATUS OF RLW

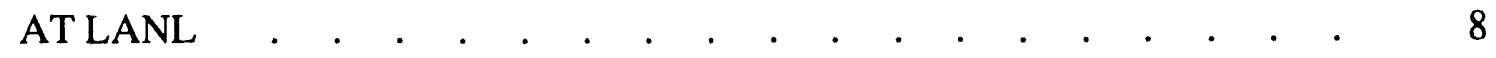

A. Historical Yearly RLW Flows . . . . . . . . . . . 8

B. Existing System . . . . . . . . . . . . . . . 8

C. Current RLW Volumes Generated . . . . . . . . . . . . . . 9

D. Building Managers and Waste Coordinators at LANL . . . . . 11

V. MEETINGS AND INTERVIEWS . . . . . . . . . . . . . . . 11

A. DOE-Level INPUT . . . . . . . . . . . . . . . . . . . 11

B. Directorate Level Interviews . . . . . . . . . . . . 13

C. Division-Level Interviews and Meeting . . . . . . . . . 18

D. Group-Level Meeting and Interviews . . . . . . . . 22

VI. DATABASE INFORMATION . . . . . . . . . . . . . . . . . . . 24

A. Questionnaires . . . . . . . . . . . . . . . 24

B. Database Information . . . . . . . . . . . . . . 24

ACKNOWLEDGMENTS . . . . . . . . . . . . . . . . . . . 25

APPENDIX A: Proposed LANL Radioactive Liquid Waste Strategic

Directive . . . . . . . . . . . . . . . . 26

APPENDIX B: A Unified Plan to Eliminate Nuclear Weapons

and Provide for the Energy Need of the World. . . . . . . 31

APPENDIX C: Director's Policy No. 105, AR10-1, and TB1001

\& $\mathrm{TB} 1002$. . . . . . . . . . . . . . . 34

APPENDIX D: Datahase Record Layout and Listings . . . . . . . . . 53

APPENDIX E: Questionnaires . . . . . . . . . . . . . . . 59 


\section{EXECUTIVE SUMMARY}

This report provides the following three primary deliverables for the radioactive liquid waste streams project, which is assigned to the Technical Engineering Support group (MEE-4) at the Los Alamos National Laboratory (LANL):

- a written report detailing the study that was performed;

- a proposed Lab Strategic Directive for managing RLW (see Appendix A); and

- an RLW future generator database ( see Appendix D).

The study provides design planning information for the Radioactive Liquid Waste Treatment Facility (RLWTF). The proposed start-up date for the RLWTF is about 2002 and the proposed life span is 40 years. To ensure that the facility is designed with the capacity to treat generated Radioactive Liquid Waste (RLW) during its years of operation, we sought to obtain the necessary data to estimate the quantities and radioactivity levels of industrial RLW to be generated into the mid-21st century. We obtained necessary data through research of historical RLW generation, from current and planned operations and facilities, and from interviews of managers at several levels.

The following are significant issues that have come out of the study.

1. Nobody at LANL has Lab-wide oversight over RLW issues. Internal organizations funded by separate defense programs and environmental management funds are not communicating about their plans related to RLW issues. Proposed plans for processes that will result in zero RLW discharge at some of the LANL facilities are confusing to the DOE. Consequently, the DOE has asked whether or not the LANL needs a new RLWTF. The proposed Laboratory Strategic Directive on RLW addresses this concern.

2. LANL has a policy and Administrative Requirements (ARs) for managing RLW. The policy assigns responsibility and the AR specifies requirements for adequate RLW waste management. At present the RLW flow metering and flow data collection system are inadequate and do not comply with RLW waste management requirements. The proposed Laboratory Strategic Directive on RLW address $s$ this concern.

3. Most RLW at LANL comes from chill water, clean-up, and wash-down operations in the facilities (not from experiments or from the processing of plutonium, uranium, medical isotopes, synthetic actinides, or the like). The chill water, clean-up, and wash-down operations are often transparent to the scientists and technicians performing their jobs. Facility RLW generation, a possible action item for waste minimization, is also addressed in the proposed Laboratory Strategic Directive on RLW.

The investigation revealed that the RLW released into the acid/rad lines is low-level radioactive waste. Most of the RLW radioactivity averages in the tens of nanocuries per liter, with maximum readings in the tens of microcuries per liter. This paper presents four possible scenarios regarding RLW. The second, and in the authors opinion most plausible of these scenarios, forecasts that a maximum of 22 million liters of RLW will be generated early in the life of the RLWTF, with that amount decreasing to about 11 million liters near the end of the proposed life span of the facility. All LANL facilities plan to minimize the hazardous components of the RLW prior to release of the effluents to the RLWTF; therefore, it is expected that effluents disposed of in the acid/rad lines will become cleaner, less acidic or caustic, and less radioactive as time progresses. Long-term goals are to minimize the volume of RLW, which explains why the volume is expected to decline even during times of expected programmatic expansion. 


\title{
FUTURE RADIOACTIVE LIQUID WASTE STREAMS STUDY
}

\author{
by
}

Alfredo S. Rey

\begin{abstract}
This study provides design planning information for the Radioactive Liquid Waste Treatment Facility (RLWTF). Predictions of estimated quantities of Radioactive Liquid Waste (RLW) and radioactivity levels of RLW to be generated are provided. This information will help assure that the new treatment facility is designed with the capacity to treat generated RLW during the years of operation. The proposed startup date for the RLWTF is estimated to be between 2002 and 2005, and the life span of the facility is estimated to be 40 years. The policies and requirements driving the replacement of the current RLW treatment facility are reviewed. Historical and current status of RLW generation at Los Alamos National Laboratory are provided. Laboratory Managers were interviewed to obtain their insights into future RLW activities at Los Alamos that might affect the amount of RLW generated at the Lab. Interviews, trends, and investigation data are analyzed and used to create scenarios. These scenarios form the basis for our predictions of future RLW generation and the level of RLW treatment capacity which will be needed at LANL.
\end{abstract}

\section{INTRODUCTION}

The primary purpose of this study is to provide design planning information for the Radioactive Liquid Waste Treatment Facility (RLWTF) at the Los Alamos National Laboratory (LANL). The RLWTF has a proposed start-up date in about 2002 with a 40-year life span. To ensure that the facility is designed with the capacity to treat the radioactive liquid waste (RLW) that is generated during its years of operation, we have estimated the quantities and radioactivity levels of industrial RLW to be generated at LANL into the mid-21st century.

We used several avenues to gather information for this study, including research of historical and current records and facilities, questionnaires, personal interviews and meetings, and existing studies. Questionnaires were sent to LANL program managers, building managers, and construction project managers, and many of the ideas for the scenarios discussed in Section II were derived from interviews with LANL managers. These interviews are also included in this report.

Two studies were reviewed to gather information applicable to this investigation: the Santa Fe Engineering (SFE) Study, which is not yet completed, and the International Technology Corporation (IT) study. Contacts for these studies are Mike Saladen and Robert Pierce, EM-8, respectively. These studies contain information on the locations and types of outfalls and provide information on which organizations might be responsible for the outfalls. However, they provide little useful information for forecasting future RLW generation. Also reviewed was the "Hanson Task," originally delegated to Chuck Grigsby of MEE-9 and later taken over by Robert Fuehrer. This task was designed to provide detailed RLW flow information on the major LANL RLW generators (CMR, SIGMA, 
TA-55, and the TA-48 facilities). But work on this task has just hegun, so information is not yet available for determining the flow volumes and RLW characteristics from these RLW generators. The information collected from these studies was given to Mort Sanders, EM-7/RLWPO. It includes useful information, including the completed questionnaires, monthly progress reports, and detailed site maps. This report attempts to summarize all pertinent information collected as a result of this investigation.

\section{PROJECTED SCENARIOS}

This study was conducted over a period of approximately 4 months, from March 1 , 1993, to June 4, 1993. Much information was gathered, within the time constraints, to aid us in making our forecasts, and the data collected suggests several possible outcomes. We decided that instead of making one prediction, it would be best to provide various possibilities and allow readers to draw their own conclusions. We therefore present the following scenarios, which are hypothesized chains of events composed from world, national, and LANL trends and from the plans, insights, and predictions for the future of the LANL based on interviews with LANL management. Each of these scenarios ends with a prediction of RLW volume. Figure 1 depicts the historical RLW flows, then continues with the future RLW flows estimated by the Scenarios in both tabular and graphical forms. The reader is encouraged to refer to Figure 1 as the scenarios are reviewed.

\section{A. Scenarios}

\section{Scenario A}

1993 to 2003: World and national conditions that might affect national security do not change. The Soviet Republics are successfully beginning to retire nuclear weapons with the help of the United States. National defense budgets continue to decline, affecting LANL budgets. Lawrence Livermore National Laboratory (LLNL) has been forced to move all nuclear materials operations to the Nevada Test Site. All DOE Nuclear Weapons Complex (NWC) facilities scheduled for closure are closed. Environmental constraints strengthen, affecting LANL defense program operations by severely restricting hydrodynamic testing and mixed-waste generation operations. Some nuclear materials testing continues at CMR, and the TA-55 facility is successfully achieving near zero RLW effluent (partly because of the limitations on mixed-waste operations). Because of LANL's failure to change its cultural behavior, especially concerning the formality of operations, it does not meet the increasingly strict national and local regulations and standards. Facilities such as the Omega West Reactor are not allowed to restart their operations. Decontamination and decommissioning (D\&D) begins with limited progress, which accounts for the generation of some additional RLW. Overall RLW generation drops by six million liters over the next 10 years.

2003 to 2040: On the world scene, some third-world countries become nuclear threats, but the U.S. sees no need for new nuclear weapons defense initiatives. D\&D continues at the LANL. Defense budgets continue to decline. and the LANL, although still maintaining the basic knowledge necessary to design and manufacture nuclear weapons, is far from its former self. Consolidation of the NWC to a single location called Complex 21 is completed in about the year 2010, and all weapons retirement and surveillance activities are moved to new facilities. It makes more sense to move all $\mathrm{R} \& \mathrm{D}$, processing, and surveillance activities to the Complex 21 facilities where the weapons plutonium and uranium materials are stored. This move also avoids shipping restrictions once the materials have been removed from the nuclear weapons. Even TA-55 doesn't last forever, and by the year 2025 it must he retired. Basically, the only weapons responsibilities remaining at 


\section{RLW SCENARIO DATA}

(Millions of liters per year)

$\begin{array}{ccccc}\text { Year } & \text { Scenario A } & \text { Scenario B } & \text { Scenario C } & \text { Scenario D } \\ 1992 & 18.5 & 18.5 & 18.5 & 18.5 \\ 1993 & 19 & 19 & 19 & 19 \\ 1995 & 18 & 19 & 19 & 19 \\ 2000 & 16 & 20 & 22 & 22 \\ 2005 & 13 & 22 & 26 & 22 \\ 2010 & 13 & 20 & 25 & 25 \\ 2015 & 10 & 18 & 26 & 30 \\ 2020 & 9 & 17 & 24 & 30 \\ 2025 & 8 & 16 & 20 & 28 \\ 2030 & 5 & 12 & 18 & 20 \\ 2035 & 5 & 12 & 15 & 16 \\ 2040 & 4 & 11 & 15 & 14\end{array}$

Historical and Scenario Data

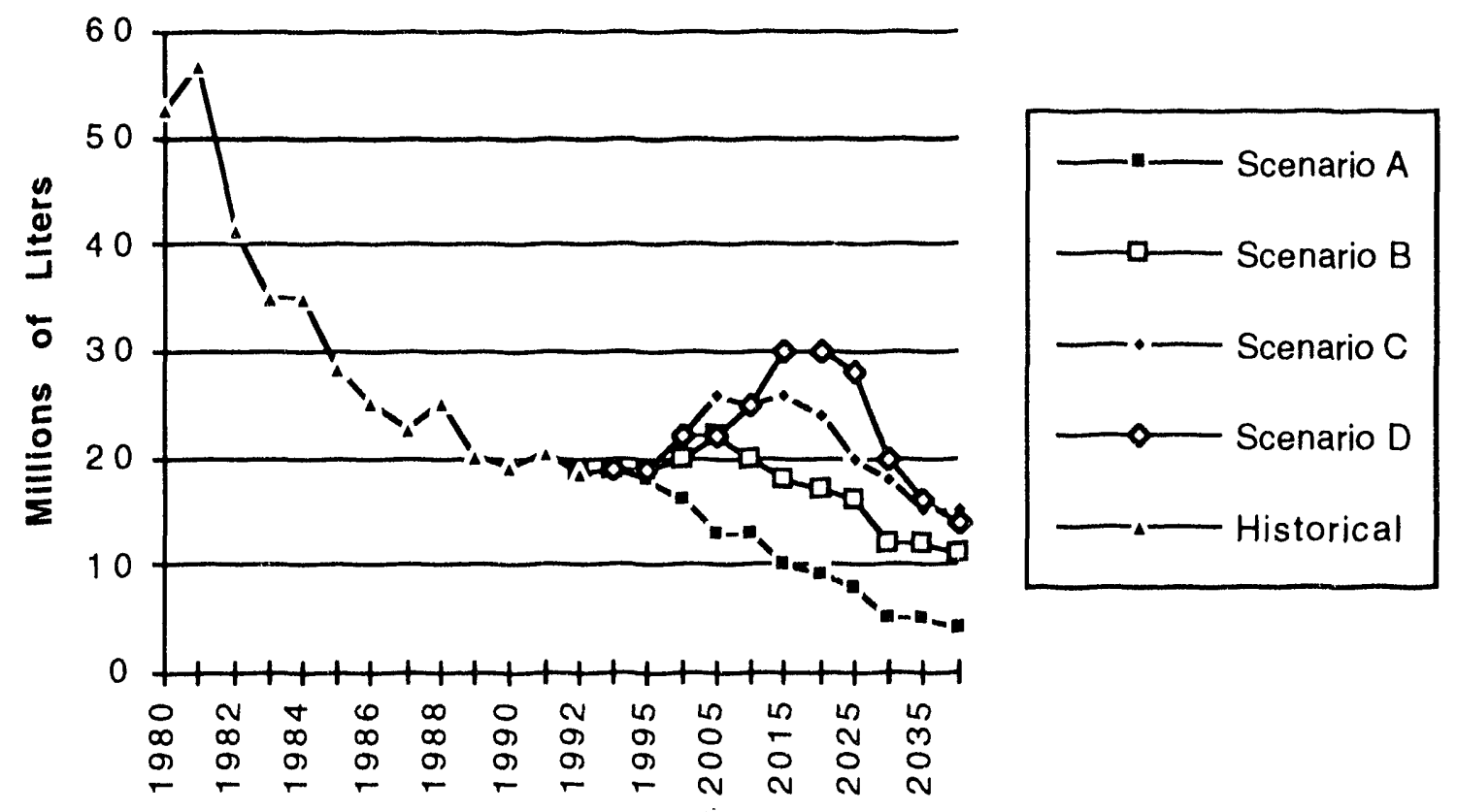

Figure 1. RLW historical data vs scenario data. 
LANL are maintenance of the nuclear weapons design and manufacturing "seed" capabilities and the theoretical R\&D using computer simulations. The volume of RLW hits a new low of five million liters per year by 2030 .

\section{Scenario B}

1993 to 2003: World conditions do not change substantially. Although the former Soviet Republics continue their efforts to adopt capitalism and democratic governments, the hardliners are making it difficult to do so, and establishing democracy is still a struggle. Nuclear weapons R\&D continues in Russia and, although treaties have been agreed upon, no nuclear weapons are actually being retired. Several third-world countries are threatening or are successful at entering the nuclear weapons capability community. The US has continued to retire nuclear weapons, and continues with its plans for Complex 21 . LLNL is forced to relinquish its weapons activities because of its proximity to California communities. LANL is designated as the nation's only nuclear weapons research Laboratory. All the nuclear weapons $R \& D$, manufacturing, and surveillance capabilities that were at the various DOE NWC plants have been transferred back to LANL (the birthplace of nuclear weapons), where a minimal capability will be maintained. Environmental controls and regulations continue to strengthen, but hydrodynamic testing and mixed-waste-generating operations are allowed to continue. LANL enjoys an increase in activity because of the consolidation. Funding for work on nuclear materials research and on "seed"-level capability maintenance actually increases. Operations at CMR, TA-55, and SIGMA all enjoy an increase in work, and, as a result, increases in RLW are observed. LANL is assigned to head a task to separate the plutonium from the Rocky Flats waste. The Omega West reactor is restarted, following the successful implementation of formality of operations and compliance with EPA and DOE regulations. RLW volumes steadily increase to about 22 million liters per year, despite waste-minimization efforts.

2003 to 2040: The world situation continues its change toward democratic governments, though not without a struggle. The US realizes the importance of keeping minimum weapons capabilities. By the year 2010, most research needed for present nuclear weapon technology is complete; however, R\&D efforts have discovered new weapons technology. New work on converting plutonium to useful energy has also begun. The Complex 21 site is complete at the Nevada Test site, and it is utilized as a nuclear material processing and storage facility. All R\&D and surveillance activities continue to be performed at LANL. RLW generation declines at a steady pace because of successes in waste minimization. Flow volumes decline from a total of 22 million liters in 2005 to a total of 18 million liters by 2015 . RLW generation declines slowly, but increased activities in the D\&D and ER areas slow the rate of decline. In 2030) the TA-55 facility is retired, and a sharp drop occurs. Rather than build a new plutonium facility, the decision is made to continue R\&D at the NTS Complex 21 facility. This means critical nuclear weapons support operations, such as those at the CMR and DP facilities, must also move there. The remaining nuclear materials activities and generated RLW continue at a steady pace of about 12 million liters thereafter.

\section{Scenario $C$}

1993 to 20(13: Ever since the break-up of the Soviet Union, there has been increasing unrest and instability between President Yeltsin and the Russian hardliners. Yeltsin weathers the several attempts to topple him, but the Russian economy does not improve, and the people have lost confidenee. The hardliners take over Russia. They cannot reunite all the former USSR countries, but Russia has somehow regained control of most nuclear weapons and is once again a power to be reckoned with. Although not as economically strong as they would like, they have regained some strength as a result of Yeltsin's changes. They have decided to keep some of the economic changes that have turned their economy around. The US, having retired thousands of its weapons according to 
the treaty, is totally surprised. By this time, all of the DOE plants scheduled to close are closed, and it is economically and politically too late to reopen them. Nuclear weapons R\&D has been consolidated at LANL and there is no acceptable reason to change now. A new nuclear weapons system is planned. Testing at Nevada is resumed. An increase in defense funding results in increased activities in all nuclear materials operations facilities, and RLW rapidly increases to 26 million liters per year.

2003 to 2040: A strange relationship evolves between the US and Russia. The two decide to continue nuclear weapons retirement, more for economic reasons than for peaceful co-existence. New nuclear weapons systems continue to be developed to replace old ones. The Complex 21 site selection and construction is accelerated. NTS is the Complex 21 site, and it is the assembly/disassembly facility and storage and processing facility of retired weapons' plutonium. Years 2005 to 2015 see a fairly constant generation of 25 to 26 million liters of RLW per year. Beyond that time, we see a gradual decline as the pressure to minimize waste increases and much of the R\&D is shifted to the NTS Complex 21 site.

\section{Scenario D}

1993 to 2003: World conditions do not change substantially. Although the former Soviet republics continue their efforts to adopt capitalism and establish democratic governments, hardliners are making it difficult, and establishing democracy is still a struggle. Nuclear weapons R\&D continues in Russia, and although agreements have been signed, no nuclear weapons are actually being retired. Several third-world countries are threatening, or successfully entering, the nuclear weapons capahility community. The US continues to retire nuclear weapons and continues with its plans to consolidate NWC Facilities (Complex 21); however, the DOE has received tremendous opposition to the idea of processing and storing nuclear materials at any of the candidate sites. Basically, each of the site states has raised opposition to shipping plutonium into their states from the other states. LLNL is forced to relinquish its weapons activities because of its proximity to California communities. LANL has been designated as the nation's nuclear weapons Laboratory. All of the nuclear weapons $R \& D$, manufacturing, and surveillance capabilities that were at the various DOE NWC plants have been retracted back to LANL for maintenance at minimal capability. The DOE also faces problems concerning the remediation of Rocky Flats waste. LANL accepts the responsibility for managing the weapons stockpile and the waste at Rocky Flats. The DOE, left without a place to process the retired weapons stockpile of $239 \mathrm{Pu}$ and $\mathrm{U}-235$, requires LANL to process retired weapons pits and the Rocky Flats waste. One consolation is that the processed nuclear material will not be stored at LANL. RLW increases to 22 million liters per year.

2003 10 204(): LANL ramps up to meet its newly imposed assignments of disassembling retired weapon pits and processing Rocky Flats waste. Shipping limitations are overeome and pits are shipped into LANL. Processing is hegun on a small scale until the larger nuclear materials processing facilities ean be built. In about 2010, the new facilities are completed and RLW increases to 30 million liters per year within 2 years. Following a 3 to 5 year learning period, RLW starts lapering off. All plutonium and uranium processing is scheduled for completion hy 2()3(). Then RLW generation declines to 10 million liters per year or less, driven hy ongoing R\&D for new weapons technology, plutonium energy extraction, and by the new Omega West Reactor replacement which gencrates negligible RLW.

\section{B. Observations}

None of these scenarios is so far fetched that it could not happen, just as no one could have predicted many of the major world events that have affected the LANL and its 
mission in such a dramatic way. As Lud Gritzo, ADO, pointed out during an interview, there are still many hardliners in Russia and in the other countries of the former USSR who would like to go back to the old regime. The probabilities are still high that the old style communist government could regain control and that the cold war could be back on.

The overall spreads ranged from 15 to 25 million liters of RLW per year at the start of facility operations, from 9 to 30 million liters around 2020, and from 4 to 15 million liters per year at the end of the expected life of the facility. The mid-range was about 20 million liters per year in 2(0)3, 19 million liters per year in 2020, and about 10 million liters per year in 2040. When designing an RLW treatment facility, one might choose the maximum of all ranges, or take the mid-range plus a 25 to 50 percent safety margin, to ensure adequate capacity.

The author's preference is for Scenario B. There are several indications that this is the most likely scenario. On the world front, Russian president Yeltsin recently withstood one of the most powerful threats from his hardliner parliament. I expect these efforts to topple Yeltsin will diminish in strength as time progresses. The Russian people have tasted democracy, and they want more freedom. The economy is shaky, but there are signs that they have enough determination to make it work. This will lead to compliance with nuclear weapons treaties and reductions in the number of weapons. The United Nations has gained respect and strength in the world and can be expected to continue policing the world trouble spots and aiding nations in trouble. United Nations' responsibilities include minimizing nuclear proliferation.

On the national scene, the trend is for the reduction of defense spending and an increase in attention to popular issues such as reducing the national deficit, national health care, taxing, and spending. The DOE has plans to consolidate the NWC complex into a "Complex 21." Paul Cunningham of LANL pointed out that Complex 21 will not be ready for about 15 years or more, and because LLNL will most likely be out of the nuclear materials operations soon, LANL is the only logical Lab to maintain the weapons R\&D and manufacturing "seed" technology. LANL's ranking managers believe that LANL is critical to the DOE, and that it is the only place where nuclear materials R\&D will be done, at least until Complex 21 is built.

\section{POLICY AND REQUIREMENT DRIVERS}

\section{A. Relevant Requirements}

As expected, there are DOE orders and LANL requirements driving the replacement of the old RLW treatment facility. LANL's policies and administrative requirements related to RLW (Appendix C) clarify the RLW management requirements and responsibilities, and they helped me to locate the individuals and groups throughout the Laboratory that generate RLW. The Director's policy No. 105, "Hazardous and Radioactive Waste Management," also makes several points that apply to RLW generation. The "Radioactive Liquid Waste" Administrative Requirement (AR 10-1), summarizes the requirements of DOE Order 5820.2a and the EPA Clean Water Act for managing and disposing of RLW. AR 10-1 also references the Technical Bulletins (TB) $1(0) 1$ and 1002, which clearly explain the RLW collection system and all of the RLW generators connected to the system. Figure 2 shows the present "Acid/Rad" system. 
TB 1001

May 29. 1992

\section{Radioactive Liquid Waste Collection System}

TA-3

South Mesa Sire

TA-3

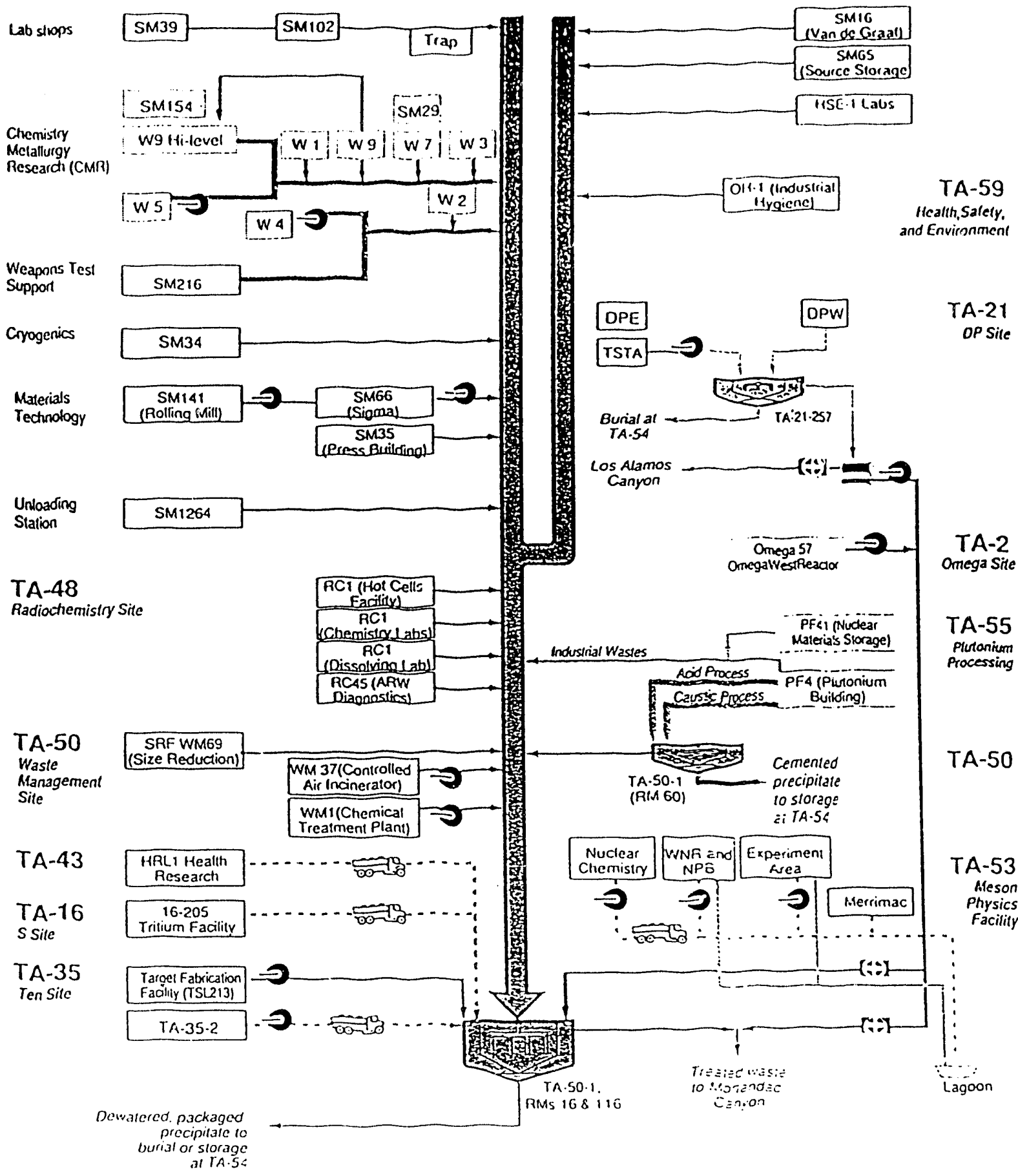

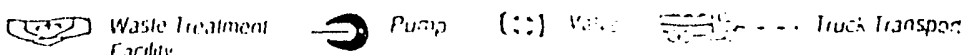

Fig. 2. Radioactive liquid waste collect system. 


\section{B. Compliance Issues}

The LANL is in varying degrees of compliance with Policy No. 105. Compliance with two points in this policy would have been most helpful for establishing an accurate baseline for future RLW forecasting. In part, the policy states thai

The LANL shall have programs for

- monitoring waste (gaseous, liquid, or solid) for the amount generated, stored, released, and disposed; and

- generating and controlling complete records to document hazardous, radioactive, and mixed wastes from generation to disposal.

The office of primary responsibility for waste management is the Environmental Management Division (EM). Group EM-7 is responsible for the present RLW treatment facility at TA-50 and for compliance with the two points listed above. Personnel at the existing RLWTF are responsible for providing information regarding RLW generation sources at LANL, including volumes and characteristics. However, the flow meters need to be calibrated and the record keeping needs to be improved. Although systems are in place to monitor RLW at each of the sources, the information is inaccurate because the flow meters are not calibrated. And although hard-copy data are gathered daily there is a lack of formal record keeping, so historical data are not readily accessible. Nevertheless, a baseline for the amount of RLW generated at LANL was established from the estimated data found in a 1990 memo from Jerry Buchholz to Anthony Drypolcher, EM-7 (see Appendix F).

\section{SYSTEM INFORMATION AND PRESENT STATUS OF RLW AT LANL}

\section{A. Historical Yearly RLW Flows}

The available yearly RLW flow totals received at the TA-50 facility were obtained from EM-7 for the years 1980 to 1992. Figure 3 shows this data. The total annual flows have declined from 52.8 million liters per year to 18.5 million liters per year during that period. The rate of decrease, however, has lessened from its average of 4 million liters (14\%) per year for 1981 to 1987 to about 1.1 million liters(4\%) per year for 1987 to 1992. The trend of a decreasing rate of flow seems, therefore, to be leveling off. If this trend continues, the RLW volumes for the next 5-year period could be above 15 million liters, but it could be less than 20 million liters annually. Caution is advised when using these figures, however, because this trend prediction uses a simple method of forecasting that does not allow for other, more complicated, factors such as changes in the number and size of future generators; programmatic fluctuations (gain or loss of nuclear weapon activities, LAMPF shutdown or modification, D\&D of facilities, etc.); changes in overall LANL mission, budget, and employee levels; and waste minimization and recycling efforts. These factors also have a significant effect on the accuracy of the RLW volume predictions that are used as component inputs to the total generated LANL RLW forecast.

\section{B. Existing System}

Table 1 lists the facilities and their descriptions and the user groups contributing to the acid/rad treatment system as of May 1992. This information is based on Technical Bulletin 1001 in the LANL ES\&H Manual and on interviews with the building managers, waste coordinators, and project leaders in the waste-generating groups. System diagrams and detailed piping drawings are available from ENG-7. Particularly useful are the ENG-C-44249 (1983), C-44430 (1986), and C-45574 (1988) series. 


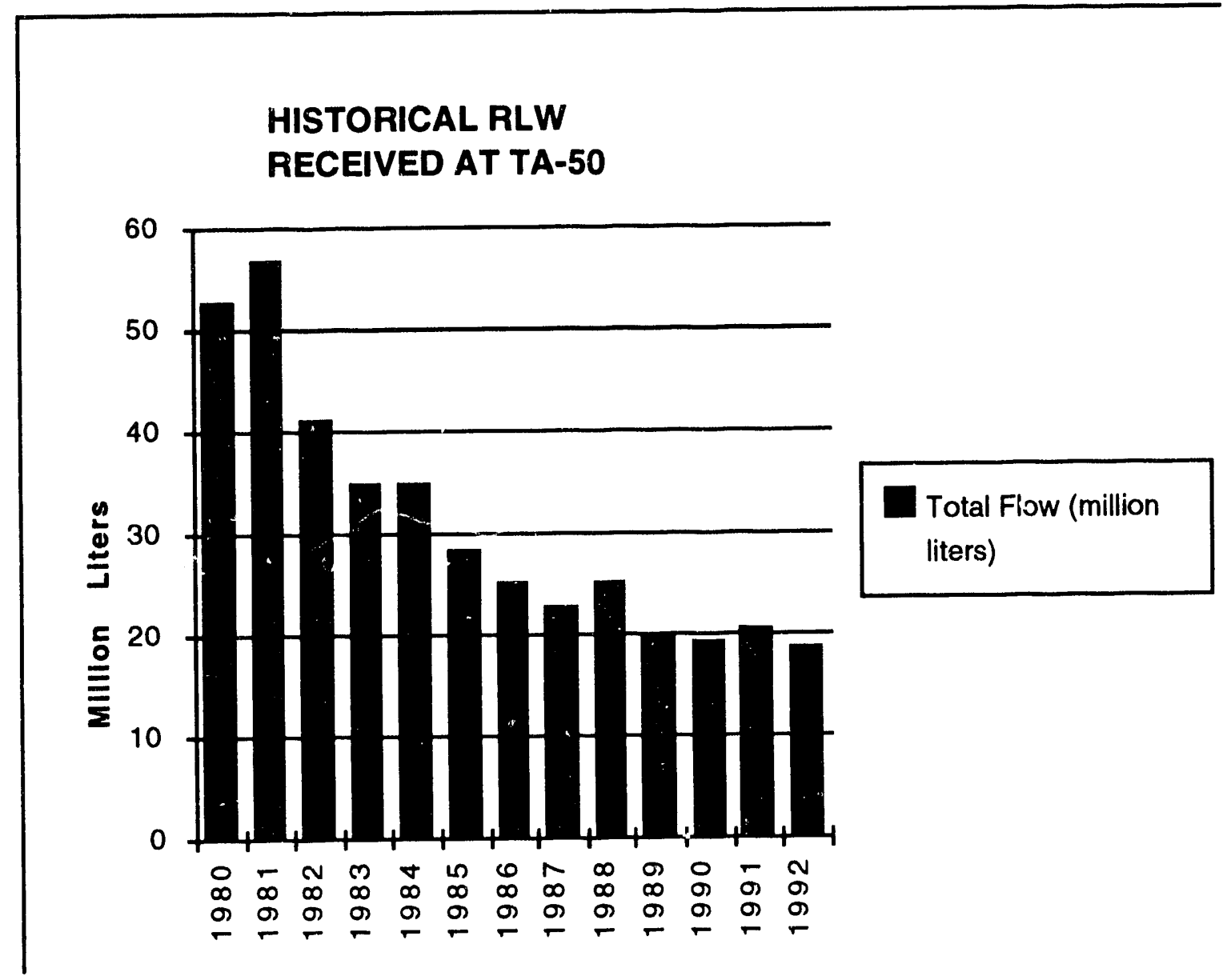

Figure 3. Historical amounts of RLW received at the TA-50 treatment facility.

\section{Current RLW Volumes Generated}

The present RLW treatment facility at TA-50 is operated by EM-7. The treatment facility monitors and collects daily RLW flows from each facility connected to the "acid/rad" lines. Since the metering system is not calibrated, flows are inaccurate and can be used only for daily comparisons and trends. There is no easily accessible automated collection system for storing and managing the data for future reference. Although some historical data are stored on magnetic media, there are, apparently, some difficulties accessing it. During the investigation, the only access to historical data were the most recent daily reports, which were stored on top of a filing cabinet; no other historical data were accessible. There are no other periodic data collections or statistical calculations for RLW generated at the generators' facilities. However, records are available of the total RLW flows that are received at the treatment facility. These records are available from 1980 to present and are considered to be accurate.

It was imperative that we have a baseline of present individual generator flows to facilitate RLW forecasts from individual generators. Because the treatment facility could not provide the information, we obtained an estimate from Jerry Buchholz, EM-7 (see memo to Tony Drypolcher, in Appendix F). 


\section{TABLE 1: FACILITIES LINKED TO RLW LINES ,OR WHICH TRUCK THEIR WASTES TO TA-50, AND THEIR RESPONSIBLE USER GROUPS}

\begin{tabular}{|c|c|c|}
\hline \multicolumn{2}{|c|}{ Facilities } & cription and User Groups \\
\hline TA-2 & Bldg. 1 & Omega West Reactor - INC-15 \\
\hline TA-3 & SM16 & Van de Graaf Facility - P-15, P-6 \\
\hline TA-3 & SM29 & $\begin{array}{l}\text { CMR-Chemistry Metallurgy Research Bldg. - CLS-DO, CLS-1, } \\
\text { MST-4 \& 5, NMT-5, 6, \& } 9\end{array}$ \\
\hline TA-3 & SM34 & Cryogenics Bldg. - CMS, P-10, MST-4 \& 7, CLS-2, CM-STC \\
\hline TA-3 & SM35 & Press Bldg. - MST-DO. Unused: scheduled for D\&D \\
\hline TA-3 & SM39 & Fabrication Shops - WX-13 \\
\hline TA-3 & SM102 & Tech Shops Annex - WX-13 \\
\hline TA-3 & SM65 & Source Storage Bldg. - HS-4, storage only; normally no waste \\
\hline TA-3 & SM66 & Sigma Bldg. - MST-DO \\
\hline TA-3 & SM141 & Rolling Mill - MST-DO \\
\hline TA-3 & SM 177 & Change trailer \& decontamination shower - HS-1 \\
\hline TA-3 & SM216 & Weapons Test Support Bldg. - P-14; no RLW generated \\
\hline TA-3 & SM1264 & Unloading station - EM-7 \\
\hline $\mathrm{TA}-3$ & SM1698 & Materials Science Lab Bldg. - MST-DO, MST-5 \\
\hline TA-16 & 205 & $\begin{array}{l}\text { WETF-Weapons Engineering and Tritium Facility - WX-5; wastes } \\
\text { are trucked to TA-50 }\end{array}$ \\
\hline TA-21 & DP West & INC operations as follows: \\
\hline TA-21 & DP3 & Scheduled for D\&D \\
\hline TA-21 & $\overline{\mathrm{DP} 4}$ & Scheduled for D\&D \\
\hline TA-21 & DP5 & Radiochemistry, INC-1 \\
\hline TA-21 & DP150) & Pu Fuel Service Bldg. - INC-OP \\
\hline TA-21 & DP East & MST operations as follows: \\
\hline TA-21 & DP152 & Lah Bldg. - MST-3 \\
\hline TA-21 & DP155 & TSTA-Tritium Systems Test Assembly-MST-3 \\
\hline TA-21 & DP209 & High-Temp Chemistry Bldg. - MST -3 \\
\hline TA-21 & DP257 & $\begin{array}{l}\text { Rad Waste Treatment Plant- EM-7. RLW is pretreated and piped } \\
\text { to TA-50 via TA-2. }\end{array}$ \\
\hline TA-35 & Bldg. 2 & $\begin{array}{l}\text { Lab \& Office Bldg. - NMT-9, N-DO. No generation of RLW has } \\
\text { occurred according to Jeff Hansen, alt. bldg. mgr; "RLW" tanks in } \\
\text { basement have received only sanitary waste water }\end{array}$ \\
\hline TA-35 & TSL213 & Target Fabrication Facility - MST-7 \\
\hline TA-43 & BLDG 1 & HRL-Health Research Lab - LS-DO; wastes are trucked to TA-50 \\
\hline TA-48 & $\mathrm{RCl}$ & Radiochemistry Labs - INC-DO, INC-6, 9, 12, 13, 15, OU \\
\hline TA-48 & RC28 & Laser experiments - INC-6, not currently generating RLW \\
\hline $\mathrm{TA}-48$ & $\mathrm{RC45}$ & ATW diagnostics - INC-6 \\
\hline TA-48 & $\overline{\mathrm{RC}}$ ? & New building under construction - INC- 15 \\
\hline TA-53 & \begin{tabular}{|l} 
WNR \\
TANKS 144 \\
\& 145
\end{tabular} & $\begin{array}{l}\text { Holding tanks } 144,145 \text { for WNR facility - EM-7, tanks are } \\
\text { periodically emptied and wastes are trucked to TA-5(); most TA53 } \\
\text { RLW, however, is piped or trucked (from Bldgs. 1, 3, 7, 28, 30, 35, } \\
\& 622 \text { to local evaporation lagoons, not to TA-50) }\end{array}$ \\
\hline TA-55 & PF4 & Plutonium Processing Bldg - NMT-8 \\
\hline TA-55 & PF41 & Nuclear Materials Storage Facility - NMT-8 \\
\hline TA-59 & $\mathrm{OH1}$ & Industrial Hygiene Bldg. - HS-5, EM-9 \\
\hline
\end{tabular}


The ratio of daily volumes among the generators is said to be relatively stable over the year, so daily printouts indicate which of the facilities are the major RLW generators. This information, and the estimates provided by Jerry, provides a basis on which to judge the accuracy of volume estimates provided by generating groups. Estimates of the future annual RLW volumes, made by the groups that generate the RLW, are considered to be underestimated by factors of 100 or more compared with the effluent estimates from EM-7. Many of the groups that generate RLW admitted that they are uncertain about their current RLW output. Consistently absent from the estimates was the volume of wash-down, cleanup, and cooling water needed to support experiments and facility ope ations. These are, by far, the largest sources of RLW and the most difficult to anticipate.

\section{Building Managers and Waste Coordinators at LANL}

With the relatively frequent changes in personnel who generate RLW it will be difficult to track possible future changes in the volume of RLW generation. Facility building managers and RI,W generator-group waste coordinators seem to be the most appropriate contacts because they often are most familiar with the overall group operations. The list of building managers and waste coordinators below were accurate as of March 12, 1993. They are lised in Table 2.

\section{MEETINGS AND INTERVIEWS}

In our efforts to gather information for predicting the future generation of Radioactive Liquid Waste (RLW), we conducted several meetings and interviews. Our purpose was to gather future plans and solicit insights for future LANL directions beyond present plans which might affect RLW generation at the LANL. All of these meetings and interviews were held between April and June of 1993. Among those interviewed were several high-level Laboratory managers who are responsible for facilities and/or projects in which RLW is generated. Many of those interviewed have programmatic or line responsibilities over nuclear weapons support facilities in which RLW is generated at the Laboratory, and others are key players in the area of waste minimization.

\section{A. DOE-Level INPUT}

The following is a synopsis of a meeting that was held at TA-66 with representatives from DOE/Albuquerque Office, from the LANL RLW Program Office, and from individuals who generate RLW at TA-55. From the input derived from this meeting, it is clear that the DOE believes that LANL is not coordinating its efforts to get approval to start the Radioactive Liquid Waste Treatment Facility (RLWTF) Project. Additional meeting notes from these interviews are given in the section entitled Division Level Interviews.

Jerry Buchholz, Waste Management (EM-7), said that DOE headquarters is willing to support the new RLWTF but that it first needs input from LANL regarding LANL's planning for such a facility. The RLW Program Office at LANL has submitted input to the DOE/AL; however, this input is being held up at the DOE Waste Minimization Office by Oren Criechfield. Oren, with Diane Morton (also of that office) attended this meeting. Oren and Diane stated that their primary goal is to ensure that those organizations at LANL that generate radioactive and hazardous wastes are taking steps to minimize wastes.

Oren said he is concerned that in their efforts to justify a new RLWTF, the LANL is not presenting a unilied front. Before this meeting, for example, the only persons he knew of from the LANL who had expressed a need for the RLWTF were those from the Environmental Management Division (EM), and he doesn't feel that EM Division represents 
TABLE 2: WASTE FACILITY LOCATIONS AND COORDINATORS

\begin{tabular}{|c|c|c|c|}
\hline $\begin{array}{l}\text { Facility } \\
\text { Location }\end{array}$ & Group(s) & Bldg. Manager & Waste Manager \\
\hline TA-2-1 & INC.-15 & Gerald Ramsey, 7-4151 & Miles Corrie, $7-4151$ \\
\hline TA-3-16 & P-15, P-6 & Debhie Clark, 7-5211 & Gregg Chaparro, 7-5211 \\
\hline TA-3-29 & $\begin{array}{l}\text { CLS-DO, } \\
\text { CLS-1, MST-4 } \\
\& 5, \text { NMT-5, } 6 \text {, } \\
\& 9\end{array}$ & Larry Haynes, $5-85.53$ & $\begin{array}{l}\text { Theresa Cull, 7-7586, and Mark Wilkerson, } \\
\text { 7-4731, of CLS-DO; Dolores Trujillo, 7-9645, } \\
\text { Adrian Lovell, 7-4088, Tom Marshall, 7-9638, } \\
\text { and Joel Dahlby, 7-9639, of CLS-1; Darryl } \\
\text { Garcia, 7-2410, ol .4ST-5; Danny Martinez, } \\
\text { 7-4060, of MEE-9. }\end{array}$ \\
\hline TA-3-34 & $\begin{array}{l}\text { C.MS, P-10, } \\
\text { CLS-2, MST-4 } \\
\text { \& 7, C.M-STC }\end{array}$ & Cal Evans, 5-1526 & Mark Hollander, 7-4377 \\
\hline TA-3-35 & MST-DO & Joe Mitchell, 7-5479 & Scheduled for D\&D \\
\hline $\mathrm{TA}-3-39$ & WX-13 & Richard Lauer, 7-2992 & Bob Hayes, 7-47.50 \\
\hline TA-3-102 & WX-13 & Richard Lauer, 7-2992 & Bob Hayes, 7-4750 \\
\hline TA-3-65 & HS-4 & Shawna Church, $5-4010$ & $\mathrm{~N} A-$ usually no waste \\
\hline TA-3-66 & MST-DO & Joe Mitchell, 7-5479 & Julia Clements, 7-1420 \\
\hline TA-3-141 & MST-DO & Joe Mitchell, 7-5479 & Julia Clements, 7-1420 \\
\hline TA-3-177 & HS-1 & Robin Bachman, 7-7171 & NA-usually no waste \\
\hline TA-3-216 & P-14, J-7 & Bill Coulter, 7-8274 & Larry Mitchell, 7-4624; Jeff Bradley, 7-7443 \\
\hline TA-3-1698 & $\begin{array}{r}\text { MST-DO } \\
\vdots \\
\end{array}$ & $\begin{array}{l}\text { (Proj. Mgr.) Mahlon Wilson, } \\
7-9555\end{array}$ & Undetermined \\
\hline TA-16-205 & WX-5 & Bob Nolen, $5-1223$ & Jay Carnes, 5-1228 \\
\hline TA-21-3 & INC-OP & Jiri Kubicek, 7-6660 & Jiri Kubicek, 7-6660 \\
\hline $\begin{array}{l}\text { TA-21-4 } \\
\text { (North) }\end{array}$ & INC-OP & Jiri Kubicek, 7-6660 & Jiri Kubicek, 7-6660 \\
\hline $\begin{array}{l}\text { TA-21-5 } \\
\text { (North) }\end{array}$ & INC-OP & Jiri Kubicek, 7-6660 & Jiri Kubicek, 7-6660 \\
\hline TA-21-150 & INC-OP & Jiri Kubicek, 7-6660 & Jiri Kubicek, 7-6660 \\
\hline TA-21-152 & MST-3 & Pete Encinias, 5-3314 & Ronald Hinsley, 7-2858 \\
\hline TA-21-155 & MST-3 & Everetı Jenkins, 7-3.521 & Dennis Hamerdinger, 7-2138 \\
\hline TA-21-209 & MST-3 & Pete Encinias, 5-3314 & Ronald Hinsley, 7-28.58 \\
\hline TA-35-213 & MST-7 & Paul Wicmann, 7-8.333 & Paul Wiemann, 7-8333 \\
\hline TA-43-1 & LS-DO & John Horne, 7-3913 & Carolyn Stafford, 7-5780 \\
\hline TA-48-1 & $\begin{array}{l}\text { INC-DO, } \\
\text { INC.-6, } 9,12, \\
13,15, \text { INC.-OU }\end{array}$ & Sara Helmick, 7-9583 & $\begin{array}{l}\text { Malt Roybal, 7-3143, INC.-DO; Michael Murrell, } \\
\text { 7-4299, INC.-6. }\end{array}$ \\
\hline TA-48-28 & $\begin{array}{l}\text { INC.-DO,-OU, } \\
\text { INC.-6 }\end{array}$ & Bryan Fearey, 5-2423 & Malt Roybal, 7-3143 \\
\hline $\mathrm{TA}-48-45$ & INC-OU & Matt Roybal, 7-3143 & Matt Roybal, 7-3143 \\
\hline $\begin{array}{l}\text { TA-48-New } \\
\text { Bldg. }\end{array}$ & INC-15 & Kevin Ott (acting), 7-4600 & Unassigned \\
\hline $\begin{array}{l}\text { TA-53-144, } \\
145\end{array}$ & EM-7 & $\mathrm{NA}-$ (holding tanks) & Dave Salazar, 7-6904 \\
\hline TA-55-4 & NMT-8 & Ron Holmes, 5-0063 & $\begin{array}{l}\text { C. (Jim) Foxx, 7-2328; Rick Romero, 5-1654; } \\
\text { Gerald Veazey, 5-3948; Dennis Wulff, 5-0545; } \\
\text { Lorenzo Trujillo, 7-2317 }\end{array}$ \\
\hline TA-55-41 & NMT-8 & C.harles Smith, 5-2716 & N/A, no RLW yet \\
\hline TA-59-1 & HS-5, EM-9 & Tom Trujillo, 5-2500 & $\begin{array}{l}\text { Richard Romero, 5-4116; John Miglio, 5-5415; } \\
\text { Sandra Cisneros-Flores, 5-5414. }\end{array}$ \\
\hline
\end{tabular}


the entire Lab. The first time Oren had seen any of LANL's RLW generators (from the DP side of the house) express their support for the new RLWTF was at this meeting. He therefore proposed that, at the very least, all the major organizations that generate RLW at LANL should be contacted and included in the planning of the RLWTF to provide support for the facility and its proposed size and capabilities. He implied that only then would he be willing to approve and pass the RLWTF proposal on to DOE Headquarters.

\section{B. Directorate Level Interviews}

The following directorate-level employees were interviewed: Paul Cunningham, Program Director for Nuclear Materials (NM); Richard Mah, Associate Director for Chemistry and Materials (CM); Jim Shipley, Program Director for the Energy \& Environment (EE), Applied Environmental Technology (AET); Lud Gritzo, Deputy Associate Director of Operations (DADO); Reed Jensen, Deputy Associate Director of Chemistry and Materials(CM); Russ Durrer, Associate Director of Physics and Life Sciences(LS). The following synopses from these interviews represent the beliefs, perspectives and insights of the persons interviewed.

\section{Paul Cunningham}

Paul believes that the Golden Age of nuclear weapons development is now past and that we are now moving into the Dark Age. He suggests that with the end of the Cold War, the government may be unwilling to maintain the nuclear weapons facilities and production personnel, so those capabilities will wither away (as evidenced by the Rocky Flats Plant (RFP) and the Mound plant, for example, which are on their way out.). On the other hand, Paul foresees that LANL will be the monastery that will capture those capabilities and maintain them at "seed" level until there is a Renaissance (i.e., until some future time when the US needs to manufacture and field a new device). This view appears to be consistent with the view of the LANL Director, that is, that the Laboratory will continue doing nuclear weapons work, but at a much diminished level.

Paul believes the Nuclear Materials programs at the LANL will continue to grow. He pointed out that aggregate funding for the nuclear materials program at the LANL has increased from $\$ 86 \mathrm{M}$ last year to $\$ 10$ ()M for next year.

Paul also believes that LANL will install a capability for processing oralloy. Potential locations for this capability are the PF-4 at TA-55 with the $239 \mathrm{Pu}$ facilities, the CMR building, or the Antares target facility. The processing capability for oralloy and $239 \mathrm{Pu}$ will include at least a minimal manufacturing capability.

Currently, LANL is the only US facility with the capability to do broad-based R\&D on plutonium. Paul believes we will also expand the amount of tritium work being done at LANL, especially when we begin tritium loading of neutron generators, which will be manufactured at Sandia in Albuquerque. Although it is expected that little or no weapons work on tritium will be done at TSTA, partly because of the international projects that are being done there, he believes that the excellent tritium clean-up facilities at TSTA might be needed to support weapons projects.

Paul, along with Richard Mah, anticipates that although parts from dismantled weapons will initially be stored at existing DOE sites, they will eventually be stored in new facilities built at one of the permanent DOE sites as a part of Complex 21. 
Paul estimates that a production facility for building new nuclear weapons could be constructed within 5 to 7 years, a time frame that meshes well with the time required to design a new device. His belief assumes, of course, that "seed" capabilities have been maintained at LANL or elsewhere and that NEPA and preliminary design bases are maintained in a "ready to go" state. He does not, however, expect any new R\&D facilities for special nuclear materials to be built until TA-55 becomes obsolete (not until 2020 to 2025).

Because he perceives that the LANL has a responsibility for the weapons stockpile, Paul says that we must continue the surveillance program in which LANL is now performing functions previously done by RFP with a budget of approximately $\$ 13 \mathrm{M}$.

Paul does not think that ${ }^{239} \mathrm{Pu}$ will be used for power generation reactor fuel within the next 15 years. In addition, he thinks it would be impractical to process RFP's low-level waste at LANL. The law that restricts the shipping of plutonium is, apparently, so onerous that packaging the material for shipping to LANL or elsewhere would be equivalent to preparing it for storage at the Waste Isolation Pilot Plant (WIPP). Thus, logically, the DOE would probably just send it to WIPP to hegin with.

Paul favors doing Rocky Flats residue treatment at Rocky Flats' Building 707, and he suggests that LANL provide the technology for this work. A six-glovebox module could treat tons of residue iı under five years.

Traditionally, LANL has worked on producing plutonium that is $99.99+$ percent pure. However, when that level of purity is achieved, large amounts of dilute plutoniumcontaining waste is produced. Paul stated that we are modifying our technology so that the objective is to produce wastes that contain essentially no plutonium. Although the plutonium product from this cleanup would not be weapons grade, it would be reasonably pure and of a stable form suitable for long-term storage.

Paul provided us with a copy of his white paper entitled "A Unified Plan To Eliminate Nuclear Weapons And Provide For The Energy Needs Of The World," which we have included as Appendix B.

\section{Richard Mah}

The DOE is in the process of selecting the sites for the weapons complex of the future (Complex 21). The primary function of this complex will be storage. As of June 1, 1993, the sites that are in the running for the storage role are ORNL, SRP, Pantex, INEL, and Hanford (these sites are in the Programmatic Environmental Impact Statement process). Although LANL has, heretofore, shown no interest in production, Richard believes that in the future, $95 \%$ of "production" will really be materials processing, and that only $5 \%$ will be associated with actual production of nuclear device components. In Rich's view, the future of the weapons complex activities will be the processing of materials that are stored (e.g., the reprocessing of plutonium pits into ingots or reactor fuel). But because the processing will be co-located with the storage facilities, Richard believes that any new R\&D facilities will also be co-located to minimize cost and SNM shipping and handling. Thus, when LANL facilities (such as TA-55) are outmoded, we can expect their functions to transfer to the storage sites. In the long run (25 years or so), Rich feels that we can expect most major RLW-generating processes at LANL to disappear. The Secretary of the DOE is scheduled to announce the storage site choices in August 1994. 
Richard is currently trying to get LANL involved in reclaiming the plutonium in the "lowlevel" plutonium waste at RFP, which is scheduled to he buried at WIPP. Some of this waste would need to be diluted before it could meet WIPP storage regulations. After dilution, this waste would require $23 \%$ of the volumetric-storage capacity of WIPP. If it were reclaimed, the volume of waste to be stored would be reduced by a factor of approximately $1(0)$, and the resultant waste would be much less radioactive. The reclaimed plutonium could be stored as an energy reserve for use in the distant future. The technology for the reclamation already exists at LANL (at TA-55), and this project could provide, perhaps, $10(0)$ jobs over 10 to 20 years. The fallout would likely be the funds needed to do the R\&D on alternative and improved recovery processes. Further, this technology could be transferred to uranium recovery, which would open even more R\&D opportunities.

According to Richard, the lack of interest in this project, among LANL management, stems from their not wanting to appear to be bringing Colorado's waste to New Mexico because, apparently, New Mexico senators have stated that they don't want Colorado's waste brought to New Mexico. That position, however, ignores the reality that the alternative plan still calls for bringing that waste into New Mexico and burying it, diluted but unprocessed, at the New Mexico WIPP site.

Richard's real concern is whether or not LANL's mission will be able to support a wide-spectrum laboratory when the Complex-21 facilities come or line. LANL management treats the core competencies for the future as basic nuclear weapon design activities, such as physics ( $X$ Division), hydrotesting ( $M$ Division), and weapons engineering activities (WX Division). In the future, these activities will be drastically downsized, and the processing activities will he moved to the Complex 21 facilities. Thus, Richard foresees that the LANL of the future will be only a small fraction of its present size, with a very limited role in the weapons complex.

In the next 10 years, Richard believes that LANL will do some stockpile surveillance. The tasks related to this work were previously done at the RFP.

According to Richard, the other sites [Oak Ridge National Laboratory (ORNL), Savannah River Plant (SRP), etc.)] are actively pursuing all aspects of future weapons work, but LANL's present direction will lead to a greatly diminished future level of weapons activity at LANL.

Al this time, Richard does not foresee Technology Transfer Initiative (TTI) activities as a major long-term source of support for the LANL. His rationale is that TTI work is a spin-off from work that is done in conjunction with the LANL's primary mission. So unless we have a diverse, viahle mission, we will not be developing new technologies that can be used by industry. In particular, if our future activities are concentrated on the currently envisioned nuclear weapons core competencies, then little of what we develop is likely to have any significant industrial applications.

\section{Jim Shipley}

We told Jim that although LANL Director's Policy No. 105 generally addresses radioactive waste management, no one is designated as being responsible for coordinating the overall RLW issue. As it turned out, Jim is already very familiar with this policy because he contributed to it. Jim agreed on the need for hetter coordination for radioactive waste management at LANL. He helieves that oversight of radioactive waste should be the responsibility of a coordinating team rather than an individual. He further suggests that the team should he composed of individuals from the Defense and Environmental Management Programs directorates, the compliance and support area at LANL, and the LANL legal 
office. He recommended that we suggest to LANL management that an institutional plan is needed for radioactive waste management, and he said that the best time to make such a suggestion would be during this current reorganization planning period.

In discussing the problems related specifically to RLW management at LANL, we pointed out the following conflicts between the LANL Environmental Management (EM) and Operations sectors. The EM sector wants a large RLW treatment facility that will enable wastes of all types and quantities to be treated at a single location. They believe that those who generate waste should minimize waste to the extent possible but that large dollar amounts should not be spent trying to treat the waste.

Reiterating his awareness of a lack of coordination of RLW management at LANL, Jim drew a diagram demonstrating that the manner in which DOE operates tends to perpetuate this problem. He pointed out that there are two separate funding offices at the DOE that create a "silo effect": the DOE Defense Programs (DOE/DP) offic:, which provides funds for the LANL Defense Programs (DP) directorate (LANL's major contributor to RLW), and the DOE Environmental Office, which provides funds to the LANL EM Directorate for clean-l p and waste management. He said that the LANL DP directorate is considering new ways to minimize waste by utilizing new processes for recirculating and cleaning up the radioactive liquids before releasing them as waste. On the other hand, the DOE Environmental Office is working with the LANL EM directorate on environmental clean-up and waste management relevant to the new RLWTF. The silo effect causes inadequate communication between the DOE/DP and Environmental Offices, and, consequently, between the LANL DP and EM directorates.

Jim would prefer that the RLW-generating organizations at LANL take advantage of both existing and new means for processing radioactive wastes to minimize the waste effluents from their facilities. To do so would mean considering new facility equipment for treating and recovering all of the actinides, uranium, and TRUs from the liquids before releasing them. This action would minimize the volume and radioactivity of the fluids released to the LANL Waste Management Group (EM-7). He also believes that the treatment capability of the LANL's RLW generators should be increased. In addition, Jim says there will always be fluids to receive final treatment because all potentially radioactive liquids must be treated and released by EM.

On the subject of future trends, we also brought up the possibility of production dismantlement of weapons. Jim felt strongly that LANL would not handle retired weapons on a large scale. Although we have the capability and have always done so on a small scale, Jim does not believe LANL will be the plutonium retirement facility. Asked what he thought should happen to the plutonium that is taken from retired weapons, Jim stated that it should be used productively; for example, to produce electrical energy in a reactor or some other form of energy extraction as opposed to disposal or long-term storage that could wind up having adverse environmental consequences.

\section{Lud Gritzo}

Lud believes that our study on the effect of current trends and policies on the future of RLW is important to the LANL and that such a study is long overdue. Lud said his sources at Lawrence Livermore National Laboratory (LLNL) have indicated that they expect LLNL to get out of the plutonium husiness within a few years. If this happens, all of the plutonium R\&D work will eventually come to LANL. 
According to Lud, the new SNM storage facility at TA-55 does not meet current needs and specifications and that $\$ 16 \mathrm{M}$ would be required to upgrade the facility should a decision be made to store additional nuclear weapons materials at LANL.

Lud believes that storage of pits from weapon dismantlement would be inconsistent with LANL's mission. He suggested that if the DOE needs additional storage capacity, they might consider the new underground facility at Kirtland Air Force Base, New Mexico.

Although the new RLW treatment facility is officially budgeted at the $\$ 134.5 \mathrm{M}$ level, Lud says the Lab would like to reduce this figure to $\$ 100 \mathrm{M}$ or less to make it more palatahle.

Lud suggested that we need to investigate whether or not the waste incinerator, if it ever comes on line, will produce RLW.

The future is very difficult to forecast because US weapons development work will be driven more by external factors, such as proliferation, chaos from the breakup of the USSR, the possible re-establishment of a hard-line regime in Russia, etc., but Lud's best guess is that weapons work in the US will decline to, perhaps, $20 \%$ of the level at which it was a few of years ago.

Lud believes that the present LANL system for handling radioactive waste is not working well, and that the problem is that the initial responsibility for radiation waste is with the researchers whose main interest is in just getting the stuff out of their labs so that they can go on with their work. However, the present system makes the researcher legally responsible for the initial handling of the waste until it is transferred to EM Division. This system forces the researchers to take on waste-handling responsibilities, responsibilities in which they have no expertise and no time to develop that expertise. In a more rational system, the researchers would interact closely with a dedicated group of environmental management professionals. These professionals would be responsible for any waste that is generated and would provide quality guidance for the safe handling of waste and for minimizing the amount of waste generated.

Lud said that at present there are small islands of interest in RLW generation and treatment at the LANL; a more unified approach to the problem would benefit the LANL. He also said that LANL is planning a series of meetings between the operations people at LANL and a team from Motorola to obtain guidance for the operations side of the reorganization.

Lud supports our future radioactive waste streams study but feels that we should take more time and make it a more in-depth study. He believes the short deadline is artificial because the DOE project authorization and the regulatory permitting processes will make it impossible to start construction in less than 7 years.

\section{Reed Jensen}

Reed Jensen said that all weapons design work has been nearly stopped and that there are no plans to design new weapons for the forsecable future. He said that the only weapons work remaining is the weapons retirement and cleanup responsibilities. He doesn't think that much of the production dismantlement and storage will be done at LANL. When asked whether he helieves LANL is likely to continue to do a minimal amount of weapons design work just to maintain our weapons capabilities and to update our weapons capabilities as the old ones are retired, he conceded that possibility. He does, however, see vigorous future activities in cleanup that will keep our chemical facilities very busy. 
Reed envisions that the generation of RLW at LANL may decrease. His prediction is hased on the reduction in nuclear weapons work and efforts in waste minimization. Other managers also predict a reduction in RLW. However, their predictions are based not only on the increased emphasis on waste-minimization procedures but also on the techniques for processing fluids to free them of contaminants.

\section{Russ Durr 4}

We explained our mission and asked Russ about ADPLS's plans for the Physics, Accelerator Technology, LAMPF, and LANSCE organizations (the major contributors to RLW in the Physics and Life Sciences (PLS) directorate). We also asked him to look into his crystal ball and give us his predictions about the effect of future trends on RLW generation.

At the time of this interview, Russ said that he foresees no change in the plans to stop funding LAMPF as of September 3(), 1993. This means that LAMPF and everything it supports, including LANSCE, is scheduled to shut down at that time He estimates that the only source of RLW after the shutdown would be from the decontamination and decommissioning (D\&D) of the LAMPF facility. He mentioned that about $\$ 15 \mathrm{M}$ of the DOE/EM60 money has heen set aside next year for D \& D.

Russ estimates that the chances of receiving funding to keep LAMPF running are small because of the number of personnel required to operate the facility and the 3 to $10 \mathrm{MW}$ of power required daily to operate it. He estimated that more than $\$ 1 \mathrm{M}$ per month is required for the power alone.

Russ said that the Accelerator Technology (AT) Division will continue, for the short term, on the GTA project, but that their future also looks uncertain.

Russ also commented on LANSC.E's RLW generation, stating that an error may have been made in the estimated volume of RLW being generated at LANSCE. Because of some faulty valves and some plumbing that was routed incorrectly, LANSCE's tanks had been receiving RLW flows from LAMPF, indicating (incorrectly) that the LANSCE operations were generating approximately $180,(K)$, liters of RLW per year. LANSCE officials estimate that the true volume has been closer to $10,(0)(0)$ liters per year.

Russ said that the Life Sciences (LS) directorate is the only area that is expected to grow, and that a small (in comparison with weapons programs facilities) increase in RLW is expected. They will he working with phosphorous-32, which is utilized in the Human Genome Program. I mentioned I had talked to Berry Willardson of the Biophysics (P-6) group. Berry has been working with phosphorous-32 for the Genomics and Structural Biology (LS-2) group and said he has heen generating a maximum of $1(K)$ gallons/week.

\section{Division-Level Interviews and Meeting}

The following division-level individuals were interviewed, again to get their predictions and insights on the current trends and policies and their possible effects on the future generation 'f RLW at LANL: Sam Pillay, Waste Minimization Project Leader; Larry Austin, Program Manager for Plutonium Processing; Jeff Weinrach, Environmental Management Waste Minimization Program Office (WMP()); Dana Christensen, Nuclear Materials Technology Deputy Division Leader; and Alfred Sattleberger, Deputy Division Leader, Isotope and Nuclear Chemistry Division (INC-DO). This section also gives excerpts from the TA-55 Radioactive Liquid Waste Generators' Meeting. 


\section{Sam Pillay}

Regarding plans for minimizing RLW at the TA-55 facility, Sam said that he and Jim Balkey are preparing a strategic plan explaining the plans for TA-55. An April 1993 draft of the plan was available from the Nuclear Materials (NMT) Division office at the time of our discussion. In essence, the plan proposes to eventually reduce $R L W$ to an absolute minimum; near zero if possible. NMT Division's plan to reduce the amount of RLW generated at TA-55 involves a combination of process flow-sheet modifications, acid distillation and recycling, waste-stream polishing, and recycling of clean water within TA55. The hope is that when this plan is fully implemented, aqueous streams from TA-55 will be safe enough to dump directly into the canyon. If this goal is achieved, a considerable reduction in RLW flow is expected from the TA-55 facility by the time the RLWTF is built.

\section{Larry Austin}

As the Lead Lab representative for plutonium dismantlement at LANL, Larry provided the following insights into the future plans and trends related to RLW. Looking at the big picture, he stated that the Laboratory Director is adamantly opposed to making Los Alamos the plutonium dismantlement and storage center (Larry thinks the storage would be needed because he is not confident that WIPP will be opening soon.). According to Larry, the technology and the capability already exist at LANL, so the only thing we would need would be the facilities (a large facility for dismantlement, processing, and storage), not only for plutonium, but also for the uranium and salts found in most weapons. However, he said, production processing of retired weapons in LANL could bring objections from Northern New Mexico residents, especially those in Santa Fe, and could lead the University of California to cancel their contract.

Larry said that the LANL Director's philosophy is that the LANL's role should be to provide the R\&D and continuing support to the DOE Complex 21 and that the Lab should not get involved in weapons production disassembly and/or storage. Larry said that DOE, on the other hand, favors the notion of having LANL be both a research and development laboratory and a processing, dismantlement, and storage facility, if necessary.

Whatever the outcome, Larry predicts that the total volume of RLW at TA-55 will remain consistent with today's flows (plus or minus $50 \%$ ), but he expects a large reduction in radioactivity. He also predicts that other RLW-generating facilities, such as LANL's CMR and Sigma facilities, will follow the same trends. He also says that this waste minimization should be accomplished utilizing present and new techniques. He was careful to point out that the intent is not to 'treat' liquid waste, but rather to continue processing the liquids for one or two more cycles before releasing them as waste. Larry believes that if the LANL does hecome involved with dismantlement, processing, and storage, the new larger facilities built to handle the production dismantlement will generate their own large quantities of RLW.

Finally, Larry pointed out the need for an overall coordinator to determine how LANL is handling the management of RLW. He says that no one is looking at the big picture, and he asks the following questions: Should RLW generators implement closed loop recirculation systems and clean up their process liquids well enough that their effluents meet minimum EPA requirements? Or should all waste be left for processing at the new RLWTF? 


\section{TA-55 Radioactive Liquid Waste Generators' Meeting}

On May 25, 1993, the following individuals attended the RLW Generator's meeting, which was chaired by Ross Garcia:

Oren Criechfield, DOE/AL/WMOSD
Dana Christensen, NMT-DO
Dave Post, EM-DO
Joel Williams, NMT-3
Ron Wieneke, NMT-2
Steve Yarbro, NMT-2
Harry Christensen, ENG/MPO
Jerry Buchholz, EM-7/RLWPO
Isaac Suazo, EM-7/RLWPO
Bill Midkiff, EM-7

\author{
DianeMorton, DOE/AL/WMOSD \\ Juan L. Griego, DOE/LAAO/PMB \\ Jeff Weinrach, EM-DO \\ Mark Dinehart, NMT-3 \\ C. L. "Jim" Foxx, NMT-2 \\ Bill Mck rly, NMT-2 \\ Ross Garci., ENG/MPO/RLWPO \\ Mort Sanders, EM-7/RLWPO \\ Rick Romero, EM-7/RLWPO \\ Alfredo Rey, MEE-4
}

Opening remarks revealed that the plan for the new Radioactive Liquid Waste Treatment Facility (RLWTF) was initiated in 1986 but that the project start has continued to slip, most recently to FY96 or, possibly, FY97. Thus, given the anticipated 7 to 10 years for design and construction, we are now estimating the completion to be in the year 2003 .

Jerry Buchholz said that DOE headquarters is willing to support the new facility but they need planning input from the Lab. The RLW Program Office has submitted input to the DOE Albuquerque office; at this time, however, that input is being held up by the DOE Waste Minimization Office in Albuquerque. During the RLW-generator's meeting, Oren Criechfield and Diane Morton of that office stated that their primary goal is to ensure that the LANL organizations that generate radioactive and hazardous wastes are taking steps to minimize those wastes. Oren clearly stated his concern that the LANL is not presenting a unified front in the area of radioactive wastes. He said that prior to this meeting, the only LANL personnel he knew of who had expressed a need for the RLWTF were those from the LANL's Environmental Management Division, and he does not feel that these individuals represent the entire LANL. This, he said, was the first time he had seen any RLW generators from the Defense Programs Directorate express their support for the new RLWTF. He therefore proposed that all of the major RLW-generating organizations be contacted and included in the planning of the RLWTF to provide, at the very least, support for the facility and its proposed size and capabilities. The implication from Oren was that only then would he be willing to support the RLWTF proposal and pass it on to DOE Headquarters.

Dana Christensen made a brief presentation explaining the short- and long-term projects that are planned and described his organization's waste minimization efforts. Dana and several other TA-55 attendees stated that the "zero-effluent" goal was misleading. He said that the TA-55 Waste Minimization Plan is not meant to completely eliminate RLW but, rather, to extract the hazardous materials and radioactive components. Although the chances are good that the volume of RLW may be reduced, he doesn't recommend that the new RLWTF be sized according to that goal. Dana emphasized that theirs is an experimental facility, not a production operation, and that they cannot easily set up ongoing treatment processes for what amounts to batch jobs. He therefore recommends that the volume capacity of the new RLWTF be based on past flows or that it be determined by some other means. Dana expressed his support for a new RLW Treatment Facility.

Dana said that the main projects for the near- and long-term operations at TA-55 are the vault work-off operations, pit surveillance, work with all plutonium isotopes, and the Residue Evaluation Program (REP) for the Rocky Flats plant. There is a great deal of 
processing to be done to completely remediate Rocky Flats. Dana used the analogy that the amount of work being done at TA-55 is only the "wart on the hog" compared with the amount of work at Rocky Flats(the hog itself). Dana expects that there will be a steady stream of work and that more RLW will be generated.

During the meeting, it was mentioned that the new RLWTF is one of the "tools" the LANL will need in order to complete its programmatic mission.

\section{Jeff Weinrach}

Jeff made it clear that his office (WMPO) serves in an advisory capacity and, therefore, has no authority to enforce the waste minimization policy. But he said that because of DOE and Lab policies (referring to the LANL Waste Minimization Policy), the general trend he is hearing from the various operations groups is that they will be required to reduce the RLW output by at least $50 \%$ or more, possibly down to zero. Jeff said this would be accomplished by installing closed loop recirculation systems that can treat the RLW and reuse the processing liquids. The process Jeff mentioned uses kelades and polymers to precipitate out metals, including radioactive metals. Jeff indicated that all of the major producers of RLW, including all wings of the Center for Materials Resources (CMR) facility, the Sigma complex, and the TA-55 plutonium facility, plan to use closed-loop systems such as these.

During the meeting, we discussed the fact that the programmatic and the environmental sides of LANL seem to be at odds with each other. The weapons and other research programs are being required to minimize waste. To do so, they are planning their own closed-loop systems and reducing, and if possible, totally eliminating RLW output. On the other hand, the Environmental Management Office is planning to build a larger and more flexible RLWTF to treat waste from all the present and future facilities. This Office is assuming that it will be the sole treatment facility, treating all of the RLW from the program side of the house. A program coordinator is needed to coordinate the activities in this area. For example, if the programmatic side gets funded for all of these closed-loop systems, then the environmental side will know that the new RLWTF will require an appropriate change in design.

\section{Alfred Sattleberger}

Alfred began by discussing the Medical Radioisotopes and Reactor Applications group (INC-15). They create medical isotopes, either at the Omega West Reactor or at LAMPF. He predicts that the Omega West Reactor (OWR) at LANL will be restarted, and that both the OWR and LAMPF will continue their operations. He said there are also plans for a National Biomedical Isotope Facility, which will cost about \$20M. This facility will use an off-the-shelf Cyclotron to generate isotopes. Whatever the neutron generator source, the medical isotope program is expected to continue into the mid-21st century.

Alfred explained the process for creating Moly 99, the planned production isotope for medical use. Briefly, the Moly 99 is one of the fission products that results when $235 \mathrm{U}$ is radiated with neutrons from a neutron source such as a nuclear reactor. A pure $235 \mathrm{U}$ target is prepared, then radiated, then dissolved, and the Moly 99 is removed. After 67 hours, the Moly 99 decays to technetium, which is used in patients to locate medical problem areas.

Al then discussed the Isotope Sciences group (INC-6), the Separations and Radiochemistry group (INC-12), and the Nuclear Chemistry and Analysis group (INC-13), the groups that are analyzing the residues left at the bottom of the cavity after a test shot at 
the Nevada Test Site (NTS). INC Division was originated to perform diagnostics for the NTS test shots. However, the need for test shot diagnostics will end in 1996 when the test ban takes effect. But Alfred says it is essential to maintain the expertise available in these groups because of the criticality of maintaining a minimum capability in this area. The expertise of these groups will also be used, for example, for analyzing the Hanford tank problems, for performing other environmental analyses, and for analyzing the new project Accelerator Transmutaition of Waste (ATW). Again Alfred predicted that the activities of these groups will continue at LANL.

In discussing the activities in the Inorganic and Structural Chemistry group (INC-1), Alfred said that this group works with small quantities of plutonium, uranium, thorium, and technetium, and on projects such as the Heap Leaching project. Most of their operations are performed at DP site, TA-21. However when the scheduled D\&D is begun at this site, INC-1 will be forced to move out. Nevertheless, Alfred believes that the CMR facility may be able to accommodate the group until a new facility is built.

Alfred predicts that good candidates for future projects are the ATW and the Hanford tank waste problem, which may bring in a total of $\$ 20 \mathrm{M}$. He said there has even been some talk of setting up a LANL office at Hanford.

\section{Group-Level Meeting and Interviews}

A meeting was held to discuss radioactive liquid waste (RLW) Generation in the Chemistry Metallurgy Research (CMR) group. Altendees were Al Rey and Terry Phillips, Technical Enginecring Support group (MEE-4); Jere Green and Ross Garcia, Engincering Division Office (ENG-DO/MPO); Karl Staudhammer, Materials Research and Processing Science group (MST-5); Jose Archuleta, Plutonium Metallurgy group (NMT-5); Sam Pillay, Nuclear Materials Technology Division Office (NMT-DO); Glenn Bentley, Analytical Chemistry group (CLS-1); Mort Sanders and Rick Romero, RLW project office; Jerry Buchholz, Waste Management group (EM-7); and Theresa Cull, Chemical and Laser Sciences Division Office (CLS-DO).

The consensus from this meeting seemed to be that most of the RLW flow volume comes from "facility"-type activities, such as facility clean-up and duct wash-down. The representatives of CLS-1, MST-5, and NMT-5 said that the activities in their group generate only relatively small amounts of "process wastes." Participants at the meeting made several major points, some of which are discussed below.

\section{Theresa Cull}

Theresa is concerned that too many uncoordinated environmental studies are going on at CMR, and she wants all persons who are making such studies to coordinate with her. She also said that INC-15 is expected to move from TA-21 to CMR within a few years, perhaps into the space currently occupied by NMT-5.

\section{Glenn Bentley}

Glenn said that CLS-1 produces small amounts of concentrated liquid wastes that contain $\mathrm{Pu}^{239}$ and other radioisotopes that are disposed of through the RLW drains. He said that all radioisotope concentrations are limited to $<0.5-\mu \mathrm{Ci} / \mathrm{l}$, and he estimated that the volume of concentrated liquid acid is on the order of $50 \mathrm{ml} /$ weck. According to Glenn, all of the wastes that contain substantial amounts of $\mathrm{Pu}^{239}$ are collected in $2-1$ bottles and returned to TA-55 because of SNM accountability requirements. 
Glenn, and others, believe that trying to collect all of the concentrated acid RLW would increase hazards, be very costly, and cause traffic problems (because of the requirements to close roads when RLW is transported by truck) and that the traffic problem could be a major consideration in maintaining an RLW collection sewer system. Thus, he believes, it would be better to use the existing acid/RLW drains and let the treatment facility handle the waste.

Glenn's opinion is that DOE Complex 21 will never be built. He said that there are a large number of people at the LANL who are trying to define what Complex 21 will look like, and, in fact, that a new complex may eventually be built. According to Glenn, this does not, however, diminish the need for a replacement for the TA-50 waste water treatment facility. He said that the experience throughout the DOE is that new nuclear facilities, in today's environment, require at least 10 years to become operational, and that if a new Complex 21 facility were to start construction tomorrow, it would be several years before it would relieve LANL from its responsibilities associated with the handling of nuclear materials. He said we must therefore maintain our infrastructure that allows us to handle these materials. This infrastructure includes facilities such as TA-55, the CMR building, and the waste water treatment facility.

Glenn further predicts that CLS-1 operations will either continue at the existing level or increase slightly over the next few years. He thinks that CLS-1 may get substantial work from the Hanford clean-up operations, but he does not expect much work from the LANL environmental ER site characterization and D\&D activities.

Glenn agreed to update the list of CLS-1 activities and develop a ballpark estimate for RLW generation at the various CMR buildings and wings. He will forward that list to Theresa, who will collect all the data and get it to Al by May 21, 1993.

\section{Karl Staudhammer}

Karl said that the list of MST-5 activities is out of date, but that he will update it and forward a ballpark estimate of their RLW production to Theresa. He said MST-5 operations are pretty irregular, that is, they generate RLW when they get a sample in, but then they might not generate anymore for quite some time.

Jose Archuleta

Jose said that NMT-5 plans to move out of CMR soon and that they generate very little RLW in CMR at this time.

\section{Jere Green}

Jere wanted to know whether duct wash-downs would continue to be done. In the general discussion that followed, the following points were made:

- The objective of the wash-down is to remove the acids from the ducts. The acids must be removed to prevent the ducts from corroding. In addition, the perchloric acid must be removed because it can react explosively with organics and with other materials that could be drawn into the hoods.

- Other methods of capturing the acids that now go into the hoods could be developed that would make it possible to eliminate the duct wash-down, which is apparently one of the largest volumetric sources of RLW. 
Jere mentioned that an upgrade of CMR is being planned, and he suggested that the minimization of duct wash-down could be one of the goals of the upgrade.

\section{Jon Neilson}

Jon said he is working on the Ulysses project with Dan Knobelock (the project leader). This uranium recycling and recovery program is scheduled to begin in 1997 . Jon stated that Ulysses was planned in conjunction with Tony Rollet's $U^{238}$ project at the Sigma Complex, and he estimates that each of these projects will generate as much as 20,000 liters per year of RLW. Although he replied in the negative when asked whether their plans include doing any processing or closed-loop recirculation of RLW to minimize the amount of RLW discharged, he said the plans could include them sometime in the future. Current plans, however, are to discharge all of the process fluids directly into the RLW/ acid waste lines.

\section{DATABASE INFORMATION}

\section{A. Questionnaires}

Three questionnaires were designed and distributed to program managers, building managers, and construction project managers (CPMs) (see Appendix E). They were asked whether or not their process would generate RLW, the name of the process and the name of the program supporting it, and the expected RLW characteristics and volumes to be generated. Approximately $80 \%$ of the program managers' questionnaires were returned, and about $20 \%$ responded that their process would generate RLW. Approximately $80 \%$ of the building managers' questionnaires were returned, and about $70 \%$ of them also responded that their process would generate RLW. The higher positive response rate was expected for the building managers because questionnaires were sent to those whose facilities are connected to the acid/rad system. The most valuable information obtained from the questionnaires was the identification of those who generate RLW at Los Alamos. The CPMs were asked to identify any projects that were planning to connect new facilities to the acid/rad system to help us identify planned facilities and responsible organizations.

Responses on the questionnaires show that those who generate RLW at LANL have little knowledge about the amounts RLW generated as a result of their experiments. For example, experimenters working with a few milliliters of an actinide in a hood at a CMR wing might estimate that they generates 3 or 4 liters of RLW per month, and certainly no more than ten. However, they usually underestimates the volume of water it takes to wash his flasks and beakers, etc. In addition, they do not account for the mop water used to clean the area, which could generate around $4(x)$ liters per month. More significantly, they do not account for the hundreds of thousands of liters of water it takes to wash down the hood ducting each month in support of his small experiment. Only after these things are pointed out do the experimenters realize their erroneous estimate. The point is that the database will have useful information about the processes such as responsible groups and program managers, contacts and waste coordinators; however, the quantities predicted may not reflect the total amount of RLW generated as a result of the processes.

\section{B. Database Information}

The database record layout and listings are provided in Appendix D. The database was produced with Filemaker Pro software licensed by CLARIS. Filemaker Pro can be run on a Macintosh or an IBM compatible using Windows by Microsoft, Inc. Appendix D contains a blank database record layout and four different database listings of the data 
collected. The blank layout shows all the information that has been stored for each RLW generating process. The other listings each present part of the information, sorted by site and building locations. The database software called FileMaker Pro can be used to present part or all the data in almost any order the user wants. The listings provided are only some of the options.

Information for the database was gathered from the questionnaires sent to program and building managers, and from personal research, phone calls, and meetings. The data included in the database are of RLW generation sources, which are expected to be in operation ten or more years. These are present or planned operations and do not include projects not yet planned for.

Note that when the individual flow volumes in the database are totaled (approximately $1,250,0(0)$ liters per year), the number is significantly smaller than the actual flow quantities (approximately 18.5 million liters) received at the TA-50 Treatment Facility in 1992, even though most of those who forecast the present operations predict that their RLW generation is expected to grow two- or threefold. The investigation found that many RLW generators are either not aware, or only partially aware, of the amount of RLW generated by the facility operations that support their R\&D experiments or operations. For example, in the data provided by TA-55, the total facility generated RLW at TA-55 (about 2(0),6() () liters/year) (see Appendix D) is low compared with the estimates from EM-7 (about $4,(0)(0,()(0)$ liters/year). It is unlikely that the minimization effort will reduce the volume that much.

Two sources of RLW are generated at each facility. One is the actual nuclear material being used by $R \& D$ experimenters (plutonium and uranium metals, various actinides, medical isotopes, and other isotopes), including the acids and caustic solutions used in the processing of nuclear materials. The other sources of RLW are the cleaning and wash-down operations, and the chill water used in facility maintenance and operations. As indicated by the estimated totals on the datahase, most of the RLW volume comes from the maintenance and facility operations in support of the experimenters, not from the actual experiments. RLW streams generated by facility operations and cleanup are by far the major source of generated RLW. Experimenters generate only a fraction of the total volume of RLW gencrated.

\section{ACKNOWLEDGMENTS}

The author appreciates the following MEE-4 personnel for their significant contributions to this project: Terry Phillips, for his help with the interviews and interview write-ups, and for creating the proposed strategic directive; Randy Mynard, for his investigation and write-up of the current system and historical and other information; and John VanMarter and Mike Henke, for their help in putting the database information together. 


\section{APPENDIX A:}

Proposed LANL Radioactive Liquid Waste Strategic Directive

Terrence Phillips, MEE-4

June 8, 1993

Owner: James Shipley 
NOTE: It is imperative that an individual be assigned the ownership of this directive. This individual must have Lab wide oversight and appropriate level of authority.

\section{Assumptions}

1. Increasingly strict regulations will be imposed on plants that treat radioactive liquid waste (RLW) that is generated by nuclear materials programs. Acceptable management of RLW by the Laboratory will require that the necessary support be available.

2. The Laboratory's generation of RLW cannot be reduced to zero as long as our programs involve nuclear materials.

3. All facilities that house processes involving nuclear materials programs will produce some RLW.

4. Technical and administrative requirements will make a centralized RLW treatment facility the option of choice.

5. The Laboratory will continue to play a major role in world-wide nuclear materials management and environmental clean-up programs.

6. The Laboratory's number-one mission in the 21 st Century will be maintaining the technical and administrative expertise needed to produce nuclear materials and explosive nuclear devices.

7. The Laboratory's existing RLW treatment plant will be ousolete by the year 2003.

\section{Unresolved Issues}

1. Future global politics could cause changes in the DOE's and LANL's missions.

2. Future waste minimization efforts at the Laboratory may reduce contaminant levels more than volumes.

3. The pace of future Laboratory environmental clean-up efforts, such as nuclear materials facilities refurbishment and/or decontamination and decommissioning, are not well defined.

4. The impact of future non nuclear weapon programs on RLW generation is not known at this time.

\section{Strategic Direction 1.0}

The Laboratory is committed to providing acceptable management of all wastes produced by its programs, including RLW. 


\section{Strategic Direction 1.1}

The Laboratory will design and implement an RLW data collection and management system to ensure that flows and waste characteristics of all RLW waste streams are determined and documented.

\section{Measurable Goals}

\begin{tabular}{|r|r|l|}
\hline No. & Date & Goal \\
\hline 1 & $7 / 93$ & $\begin{array}{l}\text { The Laboratory will establish a CQI team to study and coordinate the } \\
\text { funding and program needs on RLW issues. }\end{array}$ \\
\hline 2 & $7 / 93$ & Define the funding strategy for this project. \\
\hline 3 & $10 / 93$ & $\begin{array}{l}\text { Complete and implement a plan to upgrade and calibrate the RLW flow } \\
\text { metering system. The plan will include periodic re calibration of all } \\
\text { instruments to maintain accuracy. }\end{array}$ \\
\hline 5 & $2 / 94$ & $\begin{array}{l}\text { Complete evaluations of the present flow metering system, including } \\
\text { meter re calibrations and recommendations for upgrades where necessary. }\end{array}$ \\
\hline 6 & $4 / 94$ & $\begin{array}{l}\text { Purchase new computer hardware, if needed, and integrate it for data } \\
\text { collection into the flow metering system. }\end{array}$ \\
\hline 7 & $10 / 94$ & $\begin{array}{l}\text { Implement a formal program for the periodic re calibration of the RLW } \\
\text { flow meters. }\end{array}$ \\
$\begin{array}{l}\text { Achieve fully operational status for the computer database and storage } \\
\text { system. }\end{array}$ \\
\hline
\end{tabular}

\section{Strategic Direction 1.2}

The Laboratory is committed to designing, constructing, and operating a new facility for treating RLW.

\section{Measurable Goals}

\begin{tabular}{|r|r|l|}
\hline No. & Date & Goal \\
\hline 1 & $7 / 93$ & $\begin{array}{l}\text { The Laboratory will establish a CQI team to study and coordinate the } \\
\text { funding and program needs on RLW issues. }\end{array}$ \\
\hline 2 & $7 / 93$ & $\begin{array}{l}\text { Obtain the endorsement of line management at the Group and Division } \\
\text { level of a statement-of-need for continued processing of RLW at a central } \\
\text { facility in the future. }\end{array}$ \\
\hline 3 & $8 / 93$ & $\begin{array}{l}\text { Obtain the Director's endorsement of a requirement for a new central } \\
\text { RLW processing plant to meet the Laboratory's mission through the next } \\
\text { 25 years. }\end{array}$ \\
\hline 5 & $8 / 93$ & $\begin{array}{l}\text { Obtain DOE-AL KD-(), Authorization of Conceptual Design of a new } \\
\text { central RLW treatment facility. }\end{array}$ \\
\hline $5 / 93$ & $\begin{array}{l}\text { Obtain DOE-HQ KD-0, Authorization of Conceptual Design of a new } \\
\text { central RLW treatment facility. }\end{array}$ \\
\hline
\end{tabular}




\begin{tabular}{|r|r|l|}
\hline No. & Date & Goal \\
\hline 6 & $10 / 93$ & Begin conceptual design for a new central RLW treatment facility. \\
\hline 7 & $8 / 94$ & $\begin{array}{l}\text { Complete conceptual design for a new central RLW treatment facility and } \\
\text { submit to DOE-HQ. }\end{array}$ \\
\hline 8 & $10 / 94$ & Obtain KD-1, Authorization for Design Start, from DOE-HQ \\
\hline 9 & $11 / 94$ & Initiate Title I, Preliminary Design \\
\hline 10 & $12 / 94$ & $\begin{array}{l}\text { Initiate work to complete all required environmental law approvals for a } \\
\text { new central RLW facility. }\end{array}$ \\
\hline 11 & $10 / 96$ & Complete the environmental approval process. \\
\hline 12 & $10 / 96$ & $\begin{array}{l}\text { Complete Title I Preliminary design for a new central RLW treatment } \\
\text { facility and submit to DOE-HQ. }\end{array}$ \\
\hline 13 & $12 / 96$ & Obtain KD-2 Authorization for Final Design from DOE-HQ \\
\hline 14 & $1 / 97$ & Initiate Title II Design, Definitive Design \\
\hline 15 & $1 / 98$ & Complete Title II Design, Definitive Design \\
\hline 16 & $3 / 98$ & Obtain KD-3, Authorization for Construction from DOE-HQ \\
\hline 17 & $4 / 98$ & Issue an RFP for construction of the new facility. \\
\hline 18 & $11 / 98$ & Sign a contract for huilding the new facility. \\
\hline 19 & $9 /(12$ & Accept the completed plant from the contractor. \\
\hline 20 & $11 /(02$ & Obtain KD-4, Authorization for Operations from DOE-HQ \\
\hline 21 & $10 /(02$ & Begin start-up operations of the new facility \\
\hline 22 & $2 /(13$ & $\begin{array}{l}\text { Achieve fully operational status for the new facility and hegin shutdown } \\
\text { of the old facility. }\end{array}$ \\
\hline 23 & $10 /() 3$ & $\begin{array}{l}\text { Begin Decontamination and Decommissioning (D\&D) of the present } \\
\text { RLW treatment plant at TA-5). }\end{array}$ \\
\hline 24 & $1 /(15$ & Complete D\&D of the present RLW plant. \\
\hline
\end{tabular}

\section{Strategic Direction 1.3}

The Laboratory is committed to establishing an R\&D program directed towards reducing wastes generated during clean-up activities. 
Measurable Goals

\begin{tabular}{|r|r|l|}
\hline No. & Date & Goal \\
\hline 1 & $10 / 94$ & $\begin{array}{l}\text { Obtain funding at a seed level of \$2M. Use these funds to initiate R\&D } \\
\text { on the most critical problems and to define the R\&D program plan } \\
\text { through } 1999 .\end{array}$ \\
\hline 2 & $10 / 95$ & $\begin{array}{l}\text { Obtain approval of the R\&D Program Plan by Laboratory and DOE } \\
\text { management. }\end{array}$ \\
\hline 4 & $1 / 96$ & Begin field trials of newly developed technologies. \\
\hline $10 / 97$ & $\begin{array}{l}\text { Reduce the average volumes at RLW from cleanup activities by 50\% } \\
\text { while maintaining the total actinide content at or below historical levels. }\end{array}$ \\
\hline
\end{tabular}

\section{Strategic Direction 1.4}

The Laboratory is committed to establishing a program for performing $R \& D$ directed towards reducing RLW generation hy nuclear materials programs.

\section{Measurable Goals}

\begin{tabular}{|r|r|l|}
\hline No. & Date & Goal \\
\hline 1 & $10 / 94$ & $\begin{array}{l}\text { Obtain funding at a seed level of \$1 M. Use these funds to initiate R\&D } \\
\text { on the most critical problems and to define the R\&D program plan } \\
\text { through } 1999 .\end{array}$ \\
\hline 2 & $10 / 95$ & $\begin{array}{l}\text { Obtain approval of the R\&D Program Plan by Laboratory and DOE } \\
\text { management. }\end{array}$ \\
\hline 4 & $1 / 96$ & Begin field trials of newly developed technologies. \\
\hline $10 / 97$ & $\begin{array}{l}\text { Reduce the average level of contaminants in Laboratory RLW streams by } \\
50 \% \text { while maintaining their volumes at or below historical levels. }\end{array}$ \\
\hline
\end{tabular}




\title{
APPENDIX B:
}

\begin{abstract}
A Unified plan to Eliminate Nuclear Weapons and Provide for the Energy Needs of the World

by Paul Cunningham
\end{abstract}




\section{A UNIFIED PLAN TO ELIMINATE NUCLEAR WEAPONS AND PROVIDE FOR THE ENERGY NEEDS OF THE WORLD}

\section{P. T. Cunningham}

There is growing belief, especially among those traditionally opposed to nuclear weapons and their utility as a deterrent, that the only way to assure that the nuclear super powers do not reconstitute their stockpiles is to require that the nuclear materials essential to weapons be somehow sequestered or destroyed. Similar action is also viewed as the only acceptable way to guard against proliferation. The most common suggestions for accomplishing nuclear materials elimination are destruction, and consequent dilution with highly radioactive fission products, through burning as mixed oxide fuel (MOX) in a conventional light water reactor, or more commonly, through burning in some configuration of advanced liquid metal reactor; dilution to some benign form such as a very dilute (less than $0.2 \%$ ) glass or ceramic matrix, with or without added fission products from existing irradiated nuclear fuel; and long-term safe and secure storage. None of these options is attractive to me in that they do not in fact eliminate the materials that are the essential ingredients of weapons, only make them less accessible, and, except for storage, they introduce material forms that are themselves difficult for society to deal with and are very unattractive for the long term.

I would like to offer an alternative which I believe may have somewhat greater appeal, although certainly of broader reach than these proposals. The end result that I seek is the eventual elimination of all nuclear weapons by all states and international concensus that any nation seeking separation or enrichment production would become a pariah, subject to sanction and discipline.

My vision is to develop the technologies associated with accelerator burning of actinides as the international energy production option of the future. The technology has the potential, without the need for any scientific breakthroughs, of competing favorably with fusion. It does, in effect, utilize the fission process, stimulated by accelerator produced neutrons, to produce energy and a tractable waste form with a half life of 100 years or less. In my view it is an energy producing technology that leapfrogs traditional nuclear reactor designs without introducing major scientific uncertainties.

As a first goal, the first few accelerator burners would be developed in the U. S. and Russia, either jointly or in parallel separate projects, and used to destroy the plutonium from retired U. S. and FSU weapons. As the number of installations increased and were introduced into other nuclear and non-nuclear states, it would be possible to address the destruction of other separated plutonium and to ultimately burn the irradiated fuel that is the legacy of the traditional reactor age and one 
of the major obstacles to acceptance of nuclear power. In the ultimate, the accelerator burner could be fueled by any fissile or fertile actinide, would not incorporate any separation step that would make weapons useful materials available for proliferation, and would generate a waste form that is manageable in human dimensions.

To achieve this vision, international diplomatic initiatives would need to be undertaken along with the technology development, in order to achieve the dismantlement of all nuclear weapons and the destruction of the nuclear materials associated with them. It would also be necessary to halt the international trend toward separation of plutonium from spent civilian reactor fuel and the emergence of a plutonium based energy economy. I believe that the time is ripe for such an initiative and that there is some possibility for success. The Clinton administration will be looking for a dramatic initiative in the international arena as well as large new technological challenges on a scale comparable to the Apollo program or the SDI initiative. The next year or so offers a window of opportunity that may close in later years as more nations move toward a plutonium based energy economy. If we do not reverse that trend, we may well see plutonium traded on the floor of the Chicago Commodities Exchange in the year 2010.

The vision that I have will clearly take considerable time to realize. It is truly on a monumental scale and will challenge both the technical and diplomatic leadership of the United States. But in many ways I believe that the timing is right for such an undertaking. We have spent 50 years perfecting nuclear weapons and struggling with nuclear power, now is the opportunity to spend the next 50 years putting the weapon genie back in the bottle and developing a nuclear energy source that is inherently safer than critical core reactors, does not produce separated weapon usable materials, and creates a waste form that can be dealt with in time frames consistent with human experience. Further, the world community is ready to embrace new concepts, having experienced the end of the cold war and the emergence of a more active and effective United Nations. 


\section{APPENDIX C:}

Director's Policy No. 105, AR10-1, and TB1001 \& TB1002 


\section{SUBJECT: Hazardous and Radioactive Waste Management}

\subsection{PURPOSE}

This policy defines the basic requirements for management to be aware of, oversec, and control the gaseous, liquid, and solid wastes at the Laboratory so as to minimize the release of radioactive, hazardous and/or mixed wastes to the environment. This policy is in accordance with Department of Energy requirements to comply with applicable federal, state, local laws and regulations, DOE orders, memoranda of understanding, other agreements, and consent decrees relating to hazardous and radioactive waste management.

Discussion. This policy addresses issues of waste management. It does not address mitigating measures required for distributing, handling, and controlling radioactive and hazardous materials in the workplace. Nor does this policy establish the procedural controls necessary to manage radioactive and hazardous materials in compliance with appropriate regulatory rules and regulations. Employee, subcontractor, and public health protection concerns associated with radioactive and hazardous materials are covered in other Director's Policies.

\subsection{POLICY}

Operations involving Laboratory-generated radioactive, hazardous and/or mixed wastes shall be performed so as to

- protect the public, employees, and the environment;

- minimize generation of radioactive, hazardous and/or mixed wastes;

- comply with applicable federal, state, and local regulations for environmental protection and waste disposal; and

- continually search for effective means to improve Laboratory performance.

The Laboratory shall have programs for

- minimizing radioactive, hazardous, and/or mixed wastes including annual goals for improvement and incentives for exemplary performance;

- training personnel involved in operations that generate radioactive, hazardous and/or mixed wastes;

- collecting liquid and solid hazardous wastes and managing them in a manner which reduces toxicity and prevents the contamination of the environment;

- collecting solid and liquid radioactive wastes, applying volume-reduction techniques, and burying or storing in controlled facilities or using other compliant disposal methods;

- collecting, managing, controlling, handling, and disposing of mixed wastes; monitoring waste (gaseous, liquid, or solid) for the amount generated, stored, released, and disposed; generating and controlling complete records to document hazardous, radioactive, and mixed wastes from generation to disposal;

- providing decontamination services that promote recycling; 


\section{DP No. 105 SUBJECT: Hazardous and Radioactive Waste Management}

- providing decommissioning services for safe, efficient physical removal of facilities or equipment that have outlived their uscfulness; and

- conducting applied development and application studies to more effectively manage, treat, and reduce the volume of solid and liquid radioactive, hazardous and/or mixed wastes so that storage and disposal operations are minimized.

\subsection{RESPONSIBILITIES}

The Director and the ES\&H Council shall annually review goals for the hazardous and radicactive waste management programs and assess performance.

The Office of Primary Responsibility (OPR) shall be the Environmental Management Division (EM). The EM Division shall

- work with the Applied Environmental Technology Program Director to develop and provide the overall direction for the programs indicated above;

- collect, manage, handle, and dispose of all radioactive, hazardous, and mixed waste following receipt from the generators;

- monitor, evaluate, and report all waste streams including amounts generated;

- assist in the investigation and reporting of all compliance violations including determination of root causes;

- develop training to support this policy and the referenced programs;

- advise and assist Laboratory organizations in implementation of all programs and procedures derived under this policy; and

- work with the Applied Environmental Technology Program Director to develop goals and performance indicators for the hazardous and radioactive waste management programs.

Laboratory managers shall

- implement this policy, associated programs, and procedures and

- involve the EM Division prior to new or modified activities generating hazardous wastes.

Employees who work with hazardous and radioactive materials shall be trained and shall adhere to this policy in work activities.

The Laboratory Assessment Office shall conduct assessments of all Laboratory organizations to evaluate purformance under this policy.

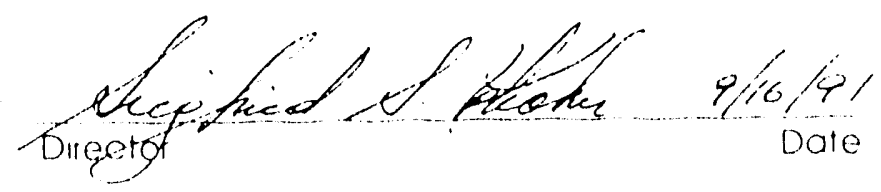


AR 10-1

Mar 29. 1992

Administrative Requirements (AR)

Introduction

Definitions

Overall

Responsibility

Waste Management Review
AR Section 10: Waste Management

\section{Radioactive Liquid Waste}

Laboratory and Departunent of Energy (DOE) policies require that the volume of radioactive liquid waste generated by Laboratory operations be reduced to a minimum and that the radioactivity of waste released to the cnvironment be kcpt as low as reasonably achicvable (ALARA). This document summarizes the requirements of DOE Order 5820.2A. "Radioactive Waste Management," and the Environmental Protection Agency (EPA) Clean Water Act for managing and disposing of radioactive liquid waste at the Laboratory. Additional guidance is available in Technical Bulletin (TB) 1001. "Radioactive Liquid Waste Collection System," and TB 1002, "Radioactive Liquid Waste Treatment and Disposal."

Batch Volume-An amount (up to a few thousand liters) of radioactive liquid waste that is segregated from the main radioactive waste stream because it needs separate treatment or because the generating site is not served by the radioactive liquid waste pipeline.

Radioactive Liquid Waste-Liquid waste contaminated or potentially contaminated with radionuclides.

Radioactive Liquid Waste Pipelines-Pipelines that carry radioactive liquid waste from various Laboratory sites to liquid waste storage and treatment facilities. (The network of pipelines was formerly referred to as the acid or industrial waste sewer system.) The Waste Management Group (EM-7) operates the waste treatment plants and maintains the radioactive liquid waste collection system from the point where a building connects to the radioactive liquid waste pipeline. Sce the appendix for additional information.

Radioactive Liquid Waste Transport-The transfer of radioactive liquid waste from Laboratory sites that are not served by radioactive liquid waste pipelines and of materials that are not allowed to be carried through the pipeline to liquid waste storage and treatment facilities.

Unless otherwise stated in this document, line managers must ensure that the requirements specificd herein are met.

Standard Operating Procedures. Each operation involving the gencration or handlirig of radioactive liquid waste requires a siundard operating procedure (SOP), which muse be prepared, reviewed, and approved as specified in Administrative Requirement (AR) 1-3, "Slandard Operating Procedures and Special Work Permits."

In addition to the review required by AR 1-3, the W'aste Management Group (EM-7) must review and approve SOPs involving the generation of radioactive liquid waste before they are implemened.

Annual Review. To cnsure compliance with SOPS and appropriate regulations, as well as to detcrmine where program improvements are neded. EM-7 is responsihte for periedic field operatonal reviews of these SOPs. The fregnency of the reviews shall be comenconsurate with the need of the partecular operation involved. 


\author{
Waste Management \\ Coordinator
}

Disposal Methods

\begin{abstract}
A waste management coordinator must be identified for each group or division that generates radioactive liquid waste. At some sites, one person may represent several groups. The waste management coordinator shall be the primary contact between generators and EM-7 and should have the authority to approve of and implement waste management matters for the group or division represented. The waste management coordinator may be the same persoll as the hazardous waste coordinator
\end{abstract} identified in AR 10-3, "Chemical, Hazardous, and Mixed Waste."

The coordinator must cnsurc that

- every operation that gencrates radioactive liquid waste is covered in an SOP:

- operating personnel are familiar with pertinent administrative requirements, SOPs, and waste management regulations;

- the volume of the radioactive liquid waste is kept to a minimum;

- the radioactivity level of liquid waste is kept to a minimum and does not exceed EM-7 rocommended limits:

- hazardous waste, as defined by the Environmental Protection Agency (EPA) in the Resource Conservation and Recovery Act (RCRA), and materials regulated by the Toxic Substances Control Act (TSCA) are not discharged into the radioactive liquid waste pipeline;

- waste streams not identified and listed under the Laboratory's National Pollutant Discharge Elimination System (NPDES) permit are not discharged into the radioactive liquid waste pipeline;

- EM-7 is notified immediately of unusual or accidental discharges that may violate waste management regulations;

- EM-7 is contacted to coordinate collection of liquid waste that does not meet requirements for discharge to the radioactive liquid waste pipeline (see "Disposal Res(rictions"); and

- radioactive liquid waste is not released to any other waste collection system. EM-7 personnel can assist in identifying connections to the radioactive liquid waste pipeline; also see the appendix.

At Buildings Connected to the Radioactive Liquid Waste Pipeline. Radioactive liquid waste (except as described under "Disposal Restrictions") must be discarded into sinks or drains that are connected to the radioactive liquid waste pipeline or to special storage tanks.

At Building Not Connected to the Radioactive Liquid Waste Pipeline. Radioactive liquid waste generated at sites not connected to the radioactive liquid waste pipeline or to special storage tanks must be collected in containers approved by EM-7 and transported to one of the tscatment plants in compliance with Department of Transportation (DOT) regulations. Generators muse store radioactive liquid waste in properly labeled containers that are located in properly posted and authorized areas. The containers must meet the requirements for secondary containment. Conlact EM.7 for container specifications. 


\section{Documentation, Certification, and Audits}

\author{
New Connections to \\ the Radioactive \\ Liquid Waste \\ Pipeline
}

Documentation. EM-7 is developing a document titled "Waste Acceptance Criteria for Liquid Radioactive Wastc Reccipt for Processing by Group EM-7" as required by Department of Energy (DOE) Order 5820.2A. When the document has been completed and approved, the generator of liquid radioaclive waste who uses a connection to the radioaclive liquid waste pipeline will be required to file a Form 1346 (ES\&H Form 10-313). Waste Profile Request (WPR), with the Environmental Protection Group (EM-8). EM-8 will review the form, assign a unique identification number, and return it to the generator. It is then the generator's responsibility to send the completed form to EM-7. This form necds to be filed only at the beginning of an operation and when diere is a significant change in the composition or volume of the discharge.

The generator of liquid radioactive wastes who uses barrels, tanks, or small containers for transferring liquid waste to EM-7 for treatment will be required to submit a WPR form for each shipment of wastes. This requirement is in addition to the requirements specified in AR 3-5, "Shipment of Radioactive Materials."

The waste acceptance criteria will also require that a Liquid Radioactive Waste Disposal Request (LRWDR) form (which is being devcloped) be completed and forwarded to EM-7 before transferring any liquid waste to EM-7 operations. This form will be submitted whenever a WPR form is required.

Certification. By signing and dating the WPR and LRWDR forms, the generators of radioactive liquid waste certify that the waste characterization information provided is complete and accurate.

Audits. The waste characterization information on the WPR and LRWDR forms will be audited periodically to determine accuracy. Generators must provide accurate information to the best of their knowledge. Inaccurate certifications may result in ceasing service to the generator until the problems are remedied.

Radioactivity Limits. Waste-generating groups must make special arrangements with EM-7 personnel for the disposal of radioactive liquid waste having an accivity greater than $0.5 \mu \mathrm{Ci} /$ liter. In the case of acid and alkaline process waste from TA-554 , total alpha concentration is limited to $60 \mu \mathrm{Ciniter}$ for acid waste and to 4500 $\mu \mathrm{Cilliter} \mathrm{for} \mathrm{alkaline} \mathrm{waste.} \mathrm{Generators} \mathrm{of} \mathrm{waste} \mathrm{having} \mathrm{an} \mathrm{activity} \mathrm{greater} \mathrm{than} 0.5$ $\mu \mathrm{Ci}$ liter must provide EM-7 with biweckly summaries of volumes and activity levels of each of the wastes discharged.

Solvents, Oils, and Liquid Chemical Wastes. Solvents, oils, and cerain liquid chemical waste must not be discarded into the sinks or drains connected to the radioactive liquid waste pipeline. See AR 10.2, "Low-Level Radioactive Solid Waste," and AR 10.3, "Chemical, Hazardous, and Mixcd Waste." For specific guidance on RCRA, TSCA, and NPDES, conLuci EM.7 or EM-8.
New connections to the radioactive liquid waste pipeline must meet specific design criteria. When new connections are proposed. EM-7 and EM-8 should be consulted carly in the project 10 ensure that all critcria are met. EM-7 provides typical specifications, drawings, and sketches for the pupeline, manholes, and electronics; EM-R provides NPDE:S permit requirements. 


\author{
Radioactive Liquid \\ Waste Transport
}

\section{Rererences}

The waste management coordinator shall arrange radioactive liquid waste transport with EM-7. Before they are transported, containers of radioactive liquid waste must be monitored and tagged. The method of tagging and transpore must be consistent with requirements in AR 3-5. "Shipment of Radioactive Materials," and the Hazardous Materials Transportation Manual. A properly completed ES\&H Form 10IA. Disposal of Batch Liquid Waste, must accompany the shipment, and all packages must have the proper DOT shipping labels attached to the transfer containers.

Authorization to Discharge Under the National Pollutant Discharge Elimination System, Environmental Protection Agency, Permit Number NM28355, effective January 31, 1990.

"Chemical, Hazardous, and Mixed Waste," Administsative Requirernent 10-3, in Environment. Safety, and Health Manual, Los Alamos National Laboratory Manual, Chapter 1 (most recent cdition).

Federal Water Pollution Control Act, as amended, 33 U.S.C. Sec. 1251-1387.

Hazardous Materials Transportation Manual, Los Alamos National Laboratory document (most recent edition).

"Low-Level Radioactive Solid Waste," Administrative Requirement 10-2, in Environment. Safety, and Health Manual, Los Alamos National Laboratory Manual, Chapter I (most recent edition).

"Radiation Protection of the Public and the Environment," Department of Energy Order 5400.5 (February 8, 1990).

"Radioactive Liquid Waste Collection System," Technical Bulletin 1001, in Environment. Safety, and Health Manual, Los Alamos National Laboratory Manual, Chapter 1 (most recent edition).

"Radioactive Liquid Waste Treatment and Disposal," Technical Bulletin 1002, in Environment, Safety, and Health Manual, Los Alamos National Laboratory Manual, Chapter 1 (most recent edition).

“Radioactive Waste Management," Department of Energy Order 5820.2A (most recent edition).

Resource Conservation and Recovery Acl, as amended, 42 U.S.C. Sec. 6901-6992k.

"Shipment of Radioactive Materials," Administrative Requirement 3-5, in Environment, Safety, and Health Manual, Los Alamos National Laboratory Manual, Chapter 1 (most recent cdition).

"Standard Operating Procedures and Special Work Permils," Administrative Requirement 1-3, in Environment, Safety, and Healih 1 anual, Los Alamos National Laboratory Manual, Chapter I (most recent edition)

Toxic Substances Control Acl, as amended, 15 U.S.C. Sec. 2601-2671. 
Referrals

Appendix

Forms
Environmental Protection Group (EM-8), 7-5021

Health Physics Operations Group (HS-1), 7-7171

Liquid Waste Section of the Waste Managenent Group (EM-7), 7-5834, 7-6904, or $7-4301$

Packaging and Transportation Safety Group of the Materials Management (MAT) Division, 7-8509

Waste Management Group (EM-7), 7-7391

Appendix. Radioacuve Liquid Waste Pipelines

ES\&H Form 10-1A. Disposal of Batch Liquid Wastc

Form 1346 (ES\&H Form 10-3B), Waste Profile Request (found in AR 10-3) 


\section{Appendix. Radioactive Liquid Waste Pipelines}

Introduction

Buildings Connected to the Radioactive Liquid Waste Pipeline

\section{Monitoring Flow}

Monitoring Leaks
Radioactive liquid waste pipclines carry radioaclive liquid waste from various Laboratory sites to liquid waste storage and treatment facilities. The system of pipelines includes a line that transfers untreated waste from swrage tank: at TA-2 and treated waste from a branch treatment plant at TA-21 to the main treatunent plant at TA. 50 .

Laboratory-Wide. The following buildings are connected to a radioactive liquid waste pipeline that carrics waste to the main treatment plant at TA-50:

- at TA-2, building Omega-1, -44, and -57;

- at TA-3, buildings SM-16, -29,-34,-35, -39, -65,-66,-102,-141,-154, -216, and -1264 ;

- at TA-21, building 257;

- at TA-35, building TSL-213;

- at TA-48, buildings RC-1 and RC-45:

- at TA-50, buildings WM-1,-37, and -69

- at TA-55, buildings PF-4 and PF-4l; and

- at TA-59, building $\mathrm{OH}-1$.

TA-53. The following buildings at TA-53 are connected to radioactive liquid waste pipelines that transport waste to storage tanks: buildings MPF-1 (laboratories), the beam channel, MPF-3S, $-3 \mathrm{M},-3 \mathrm{~N},-7,-28,-30$, and -622 . From the storage tanks, the waste is pumped either directly into the lined lagoon at the east end of TA-53 or into tank trucks, which then transfer the waste to the lagoon nr to TA-50.

TA-21. The following buildings at TA-21 are connected to the radioactive liquid waste pipeline that transports waste to the branch ireatment plant at TA-21-257: buildings DP-3, $-4,-5,-150,-152,-155$, and -209.

Radioactive liquid waste pipelines at each generator site are equipped with metering devices that transmit flow data through intelligent remote multiplexers to a computer at TA-50-1. A graphical plot of these data informs waste management personnel of normal flow volumes and any unusual conditions.

The main radioactive liquid waste pipeline is double-contained; that is, radioactive liquid waste flows through an inner pipe that is surrounded by an outer pipe. If the inner pipe leaks, the liquid drains into the outer pipe and flows downstream to the nearest manhole, where a detector transmits an alarm to the computer at TA-50-1.

If both lines rupture accidentally, the Waste Management Group (EM-7) must to informed as soon as possible to lake correcuve actions and to aler emergency personnel. Upon notification by EM-7, personnel from the Health Physics Operations Group (HS-1) and the Environmental Protection Group (E.M-8) immadiately tegin sampling and monitoring the leak. 
Technical Bulletins (TB)
TB Section 10: Waste Management
Radioactive Liquid Waste Collection System
Introduction

\section{Overall Description}

Buildings Connected to the Radioactive Liquid Waste Pipeline
In its research and development efforts to solve problems of national interest, the Laboratory generates radioactive liquid waste that must be managed in ways that limit release of radioactivity to the environment. This technical bulletin describes the Laboratory's radioactive liquid waste collection system, which is composed of an extensive main system and four other separate systems that serve TA-21, TA-55, TA53, and TA-35. (Sec Fig. 1.)

The radioactive liquid waste systems carry radioactive liquid waste from various sites to liquid waste storage and treatment facilities. In some cases, radioactive liquid waste is transported to the treatment facility by tank truck. Requirements for managing and disposing of radioactive liquid waste at the Laboratory are found in Administrative Requirement (AR) 10-1, "Radioactive Liquid Waste."

The collection system for the main radioactive liquid waste pipeline is a network of over 25,000 ft of pipeline connected to buildings on South Mesa and along Pajarito Road; it terminates in storage tanks at TA-SO-2.

The TA-21 system collects waste from TA-21, DP East and DP West, and a treatment plant at DP-257. A pumping station and cross-country pipeline transfer the treated waste from TA-21 to TA-50-2. Stored radioactive liquid waste from TA-2 is also injected into the pipeline as it crosses Omega Canyon.

The TA-55 system collects waste from TA-55 and discharges it through underground pipes to storage lanks at TA-50-66 and TA-50-2.

The radioactive liquid waste pipeline system for TA- 53 consists of three subsystems serving one or more buildings. Each subsystem empties into a separate storage facility. The two largest storage facilities are equipped to transfer the waste by pipeline to a lined lagoon for treatment; the third uses pumps to transfer the stored waste to a tank truck for transfer to the lagoon or to TA-50-2.

Truck transport is also required for removing stored radioactive liquid waste from TA-16-205 and TA-35-2 and for transferring small quantities of waste excecding administrative control levels at TA-43-1. Nonradioactive/nonhazardous waste at TA. 43-1 is pumped to a pipeline that transfers it to the sewage treatment plant at TA-3.

The following buildings are connected to the main radioactive liquid waste pipeline:

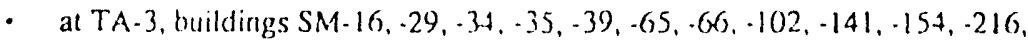
and -1264 ,

- at TA-35, building TSL-2.13;

- at TA.AR. buikdings RC. 1 and RC..5;

- at TA-50, buldding!s WM-1, -37, and -69); and

- at TA.59, building OH-1. 
IB 1001

May 29. 1002

Radioactive Liquid Waste Collection System

TA-3

South Mesa Sire

TA-3

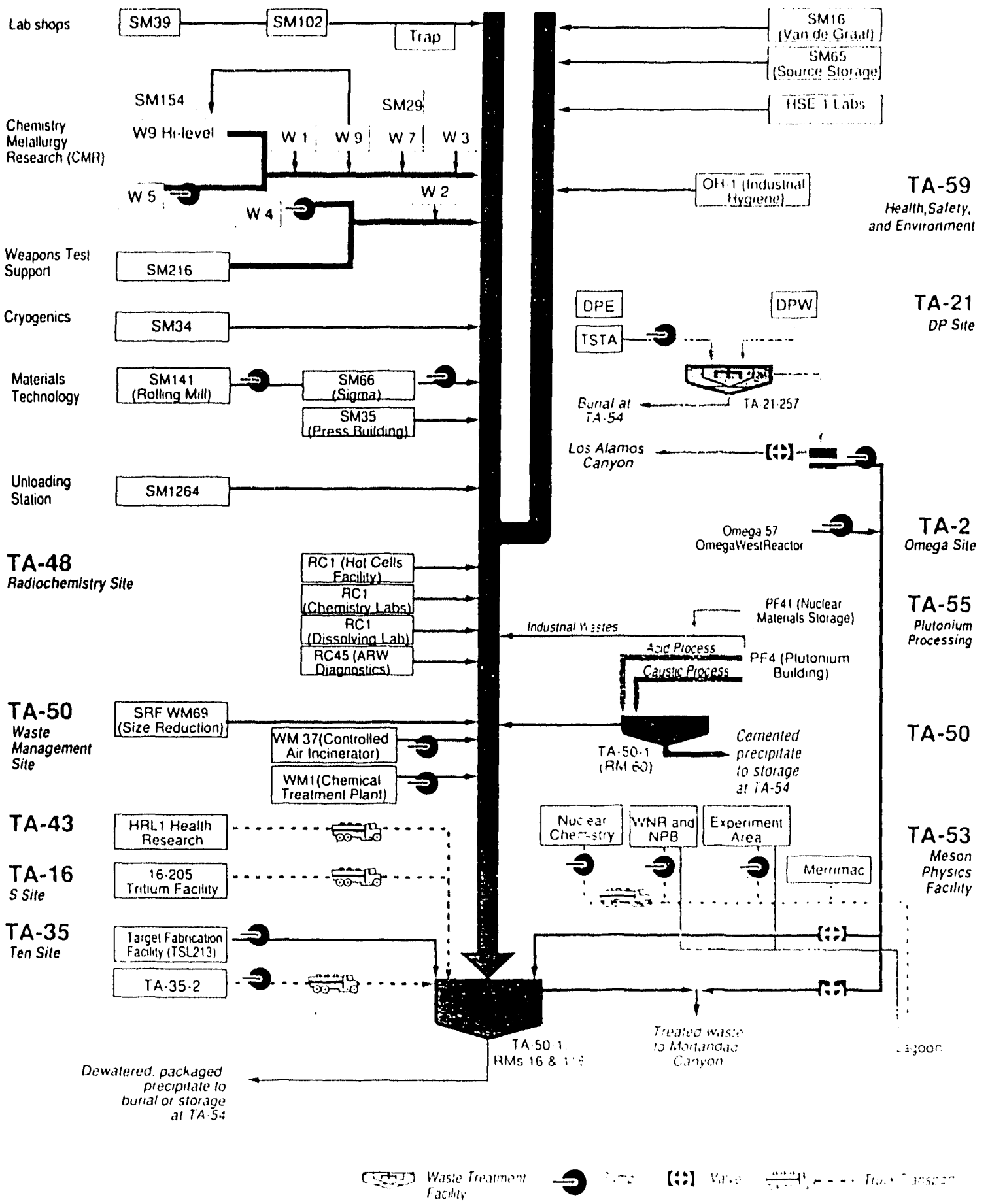

Figg. I. Radionative liquid waste coll: won system 
Was " Monitoring and Minimization

Pipeline

Construction
Buildings on the TA-21 system are listed below:

- at DP East, buildings DP'-152, -155, and -209;

- at DP West, buildings DP-3, -4, -5, -150, and -257; and

- at TA-2, buildings ()mega-1, -44 , and -57 .

Buildings on the TA -55 system are PF-4 and PF-4I.

The TA-53 system serves the accelerator beam channel, structures $3 S, 3 \mathrm{M}, 3 \mathrm{~N}$, and buildings MPl-1, 7, -28, -30, and -622. MPF-1 also houses a radioactive liquid waste storage tank for the MPl:-1 laboratories. Radioactive liquid waste from the beam channels is stored in underground tanks in MPF-68 and -69. Storage tanks for radioactive waste associated with the Weapons Neutron Rescarch and Neutral Particle Beam programs are located in WNR-144 and WNR-145.

Changes in the volume of waste flowing into the main radioactive waste collection systent are monitored by flow meters installed in the waste lines near the area where each line leaves the building. The waste volume data are transmitted to a TA-50-1 computer that produces a plot of the waste flow. To minimize the volume of radioactive liquid waste discharged into the sysiem, the Waste Management Group (EM-7) investigates any unusual increase in waste volume to deternine if it was planned or accidental and recommends any necessary corrective action. Discharges from pumping stations in the TA-21 system are monitored similarly.

In the TA-55 system, known volumes of plutonium process waste from PF.4 are directed to computer-monitored storage tanks at TA-50. Data on volumes and total alpha activities are cransmitted to EM-7 biweckly.

In the TA-53 system, data on the depths of radioactive liquid waste in the computermonitored storage tanks are also continuously available.

The main waste collection system is designed to be acid-resistant from the building in which the waste is generated to a neutratization station in TA-50-1. Between each building and the first manhole outside the building the lines are double-encased (pipewithin-a-pipe) fiberglass-reinfored pipe (FRP), and the pipes within all manholes are stainless sted. Between manholes, which are placed approximately 50() ft apart, the lines are double-encised polyethylene.

In the TA.21 system, collection lines are stainless steel at DP West, carton steel from DP - 257 to TA-50-? and are either vitrified clay pilk (VCP) or carlson steel at DP fast. Connecting lunes from l'A - 2 alre also callon steel.

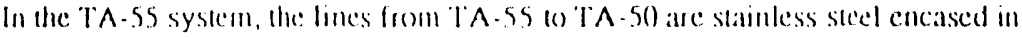
pxlyvinyl chloride: (P'(')

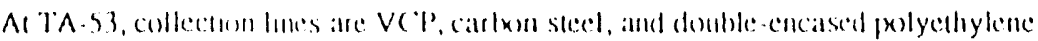


Manhole Construction

Tank Truck Unloading Stations

\section{Pumping Stations}

The standard manhole in the radioactive liquid waste collection system is constructed of reinforced concrete, with the walls and bottom slab sealed inside and out against leakage. Small steel trusses anchored in the walls clamp the inner polycthylene pipe to restrict its lengthwise expansion or contraction, and the stainless stecl piping within the manhole is fitted with taps for pressure-testing the inner line between manholes. All manholes are equipixed with electronic sensors that detect moisture in the outer polyethylene line or the mantwole and eransmit an alarm to the computer at TA-50-1 if moisture is present.

A tank truck is used to carry radioactive liquid waste from Laboratory sites (as shown in Fig. 1) to (wo unloading sites in accordance with the Los Alamos Hazardous Materials Transportation Manual. If winter rad conditions prevent a tank truck carrying radioactive liquid waste from reaching TA-50-2, the driver is instructed to use an alternative station southeast of SM-66 at SM-1264 for unloading; this station is covered, which facilitates operations in inclement weather. At SM-1264, radioactive waste from tank trucks is drained into an underground storage tank installed inside a concrete vault; at an appropriate time, valves installed on the piping from the storage tank are opened, and the waste is drained into the main collection system.

At TA-50-2, radioactive waste from tank trucks is unloaded into :nderground storage lanks.

The following pumping stations are part of the radioactive liquid waste collection system:

Pumping Station

TA-2-57

TA-3-29, Wings 4 and 5

TA-3-66

TA-3.141

TA-3-154

TA-16-205

TA-21-223

TA-21-257

TA-35-2

TA- $50-37$

TA-53.1

TA-53-68, - 69

TA-53-144, - 145

TA.59-1

\section{Bumps 10}

Cross-country pipeline to TA-50-2

Sump pumps to storage tanks, storage tanks to collection system

Main collection system

Pump discharge line at SM-66

Stainless steel storage tanks to main collection system

Tank truck

TA.21-257

Cross-country pipeline to TA-50-2

Tank uruck

Main collarion system

Tank eruck

TA. 53 lagiwn or tank truck

TA.53 lagown or tank truck

TA.59-1 radioaclive liguid waste line within the building? 
Computer Monitoring for l.eakage in the Pipeline

References

Referral
Infiltration and exfiltration are major concerns for radioactive liquid waste pipeline managers. The Los Alanos system has been designed to minimize infillration, which results in an increased volume of waste to be treated, and exfiltation, which results in environmental contamination.

The main pipeline system, the TA-55 system, and much of the TA-53 system use double-contained pipe that drain any in- or exfiltation into the nearest duwnstream manhole; the TA-21 systern is largely welded carbor or stainless stecl piping. Where lines are double-contained, the mantoles are equipped with sensors that alarm when liquid enters from either the pipeline or an opening in the manhole. The sensors are hard-wired to intelligent multiplexers that relay an alarm to a computer at TA-50-1. Because the computer is manned only $40 \mathrm{~h} / \mathrm{wk}$, the alarm system is connected by way of telephone pairs to a continuously-manned utility control center. Control center operators contact EM-7 personnel when an alarm is received during off-hours. Should there be computer problems at TA-50 during off-hours, a voice synthesizer automatically alerts EM-7 personnel by telephone.

Leakage alarms are investigated immediately, and corrective action is taken. High liquid levels in sumps or storage tanks, low pH readings, and high flow rates also set off alarms. The computer is also programmed to receive flow-rate data, tank waterlevel information, and $\mathrm{pH}$ readings and can operate remote valves and pumps in the system. Leakage from non-double-contained lines is measured by comparing the volume of waste discharged by the generator with the volume received at the storage facilities.

Emelity, L. A., ct al., "A New Continuously Monitored Collection System for Liquid Industrial Wastes," Journal Water Pollution Control Federation 56 (11), 1192-1198 (1984).

Hazardous Materials Transportation Manual, Los Alamos National Laboratory document (most recent edition).

"Radioaclive Liquid Waste," Administrative Rquirement 10-1, in Environment Safety, and Health Manual, Los A lamos National Laboratory Manual, Chapter 1 (most recent cdıtion).

Waste Managemene Group (EM-7), 7.7391 
Technical Bulletins (TB)

Introduction

Waste Types
TB Section 10: Waste Management
Radioactive Liquid Waste Treatment and Disposal
Environment, Satety, and Health Manua

Los Alumos National Lunorotory
'This technical bulletin describes the Laboratory's radioactive liquid waste treatment and disposal system, which is operated and maintained by the Waste Management Group (EM-7) and consists of three physical/chemical plants and a lined lagoon. The cypes of radioactive liquid waste, the waste treatment processes, the disposal methods for treated waste, and the control of precipitates are also discussed. Requirements for managing and disposing of radioactive liquid waste at the Laboratory are found in Administrative Requirement (AR) 10.1, "Radioactive Liquid Waste," and a detailed description of the radioactive liquid waste collection system is found in Technical Bulletin (TB) 1001, "Radioactive Liquid Waste Collection System."

The treatment and disposal system includes a 950-liter-per-minuic (lpm) waste treatment plant at TA.50-1, Room 116; a 95-1pm plant at TA-50-1, Room 60; and a $475-1 \mathrm{pm}$ plant at TA-21-257. At each plant the radioactivity of the waste is concentrated into a precipitate that is separated and dewatered. The dewatered precipitate is appropriately packaged for storage or disposal, and the decanted liquid from the TA-50-1. Room 116, plant is relcased to the environment if tests indicate that treatment met all applicable requirements. Decanted liquid from the TA-50-1, Room 60, plant is treated again in the larger TA-50 plant; the TA-21.257 decant is pumped to TA-50 for treatment and disposal.

Decay of radionuclides (except tritium, which evaporates) takes place in the lagoon at TA-53. The lagoon is large enough to contain the entire influent without overflowing.

Radioactive and chemical constituents in the influent waste treated by each facility differ widely in variety and concentration.

TA-50-1, Room 116. Waste transferred to the main waste treatment plant at TA-50-1, Room 116, is generated in laboratories, shops, an accelerator, a hot-cell facility, and a small reactor. This plant processes more than $85 \%$ of the total treated volume of waste and has the greatest need for operating manpower, supplies, electrical power, and maintenance. The waste processed in Room 116 is very dilute and has very low concentrations of beta or gamma emitters or hazardous chemicals (mercury, lead, arsenic, cyanide, etc.). The primary concern in treating this waste is the presence of plutonium, americium, and uranium, but concentrations of these elements are low enough to categorize the waste as "low level," that is, $<100 \mathrm{nCi} / \mathrm{g}$ of alpha activity.

From 1986 through 1990, the annual volume of radioactive liquid waste treated at this plant ranged from 19 to 25 million liters. Alpha activity in the untreated waste during this period was between 1.39 and $4.04 \mathrm{Ci} / \mathrm{g}$; beta activity was between 0.47 and 1.30 $\mathrm{Ci} / \mathrm{g}$.

TA.50-1, Room 60. The radioactive liquid process waste from TA.55 is transferred to the treatment plant at TA-50-1, Room 60. It is much more concentrated in plutonium and ancricium than the waste processed in the TA-50, Room 116, plant and is categorized as transuranic (TRU) waste (>100 nCi/g). In addition, one waste stream is highly acidic because of high concentrations of nitric and hydrochloric acid: another is highly basic beause of high concentrations of sodium and potassium 
Waste Treatment Processes hydroxide. A third stream from TA. 55 contains water generaled from floor washing, sink drainage, cte. It contains no TRU waste and is diverted to storage in TA-50-2 and held for later treatment in the TA-50-1, Room 116, plant. All throe streams may contain very small amounts of hazardous chemicals.

From 1986 through 1990, an annual average of 152.400 liters of radioactive liquid waste containing an average of $70 \mathrm{Ci}$ of plutonium and $64 \mathrm{Ci}$ of annericium was treated in Room 60.

TA-21-257/TA-2. The waste processed by the TA-21-257 plant is more dilute in both radioaclivity and chemical concentration than the waste processed in Room 116 at TA-50-1. It.is a mixture of laboratory and janitorial waste. Laboratories that generate liquid radioactive waste tightly control alpha crmitters. During each of the past four years, 2.1-5.2 million liters of radioactive liquid waste containing $0.002-0.050 \mathrm{Ci}$ of alpha activity were treated at the facility at TA-21-257. Beta activity was, on the average, about $21 \%$ of these levels.

The volume of radioactive liquid waste transferred from TA-2 through the pipeline for treatunent at TA-50 has typically been about 66,000 liters per year.

The TA.53 Lagoon. The waste pumped to the lagoon at TA.53 is primarily cooling water blowdown and lcakage from various units (pumps, etc.) in the system. This cooling-system water was demineralized initially, and any minerals present are the result of pipe erosion. Radioisotopes of concern are tritium and ${ }^{7} \mathrm{Be}$. Isolopes of iron, sodium, manganese, cobalt, and cesium are also measured, but they are present in much lower concentrations and have shor half-lives. The lagoon also contains small quantities of radioactive liquid waste from MPF-1 (usually less than one tank, 5000 liters, per year). This waste can vary considerably in radioactive and chemical concentration, but both are generally very low.

In recent years, waste transferred to the lagoon has typically totaled approximately 1 million liters per year and contained approximately $90 \mathrm{Ci}$ of ${ }^{3} \mathrm{H}, 30 \mathrm{Ci}$ of $\mathrm{Bc}, 0.27$ $\mathrm{Ci}$ of ${ }^{\circ} \mathrm{Co}$, and small quantities of various other radioisotopes.

TA-50-1, Room 116. The plant at TA-50-1, Room 116, is equipped with duplicate flash mixers, concentric circular clarifloceulators, a single anthracite/sand filter, duplicate strong and wiak cation resin ion-exchange columns, and a precoat-lype of rotating vacuum filter. Five chemical feeders are available to inject chemicals into the flash mixers; a carton doxide feeding system can recarbonate filter influent to stabilize the calcium cartxonate; an acid feeding system can adjust the pH of treated waste; and facilities are available (o) use nitro acid to regenerate the ion-exchange columns.

The plant is equipled to treat waste al a rate of 950 1pm when the flash mixers/clariffoceulators are operating in parallel and at a rate of $475 \mathrm{lpm}$ when they operate in series. Because of reduced volumes of influent and the requirement for removing grealler amounts of alpha radioaduvily, the plant has twen operated in series during the last few years

The leatment prexess tegrins in the main plant with the thorough mixing of waste plus hydrated lime and lente sulpholle for atout 30 s in the flash mixers; followin!

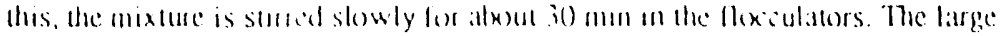

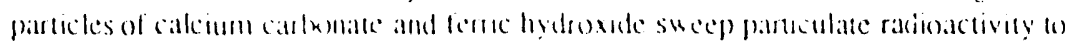


Disposal of Treated Waste the bottom of the clarifiers as the mixture seules for $2 \mathrm{~h}$. Slow-moving scrapers then carry the precipitate to a central hopper. The radioactive precipitate is drained periodically from the hopper and is moved to a separate storage area for additional concentration by sedimentation and decantation.

Strong and weak cation-exchange resins are used to remove soluble radioactivity in the filtered raw waste, particularly compounds containing plutonium, strontium, and cesium. It is preferable (o) use this ion-exchange process before the chemical treatment because the chemical treatument adds iron and calcium to the waste, thus consuming some of the capacity of the resins to attract radioactive ions. However, the plant is plumbed to permit ion-exchange treatment either before or following the physical/chemical treatment.

When the exchange resins reach hardness exhaustion they are regenerated with dilute nitric acid. The regenerant solution, which contains much of the radioactivity collected by the resins, is stored for later concentration by wiped-film evaporation. The concentrate is packaged for storage or disposal depending upon the level of longlived alpha emitters that it contains (that is, whether the concentrate is a TRU waste or low-level waste).

TA-50-1, Room 60. The waste treatment plant at TA-50-1, Room 60, is much smaller than the Room 116 facility. Its design is based on the same physical/chemical processes as Room 116, but it treats waste with significantly greater concentrations of plutonium and americium; waste is processed at $951 \mathrm{pm}$. Room 60 does not use parallel units as the main plant does and does not have ion-exchange capability. This plant has facilities for precipitate storage within the room, and because of the levels of plutonium involved, the storage tank is equipped with a neutron monitor and alarm.

TA-21-257. The horizontal cross sections of the waste treatment units at TA-21-257 are rectangular rather than circular, and there are no duplicate units. The treatment process is a ferric hydroxide/calcium carbonate precipitation procedure as in the main plant. The waste sent to this facility does not contain soluble radioactive compounds that require ion-exchange treatment, and no ion-exchange columns are provided. Waste is processed here at $475 \mathrm{lpm}$.

The TA-53 Lagoon. Waste collected in the storage tanks at TA-53 is transferred to a 0.47-ha ( 1 acre) lined lagoon for evaporation. The lagoon is designed to contain the radioactive waste without overflowing and is lined to prevent leakage. It has a bentonite clay boltom and concrete sidewalls, all covered with welded hypalon liner matcrial.

TA-50-1, Room 116. Waste treated in the Room 116 plant flows to storage at TA-50). 2. If, after analysis, it meets Deparument of Energy (DOE) standards for maximum levels of radioisotopes in discharges to the environment and Environmental Protection Agency (EPA) requirements (National Pollutant Discharge Elimination System of the Federal Water Pollution (ontrol Act) for certain other chemical and biological characteristics of dischargen to navigable streams, the waste is pumped to Mortandad Canyon north of $\mathrm{TA}-50$. 
Control of Precipitates
TA-50-1, Room 60. Treated waste from the TA-50-1, Room 60, plant is pumped to the main treatment plant's raw waste storage tanks and is treated again in this larger facility in Room 116. It is cventually pumped to Mortandad Canyon as a part of the main plant effluent.

TA-21-257. Treated waste from TA-21-257 is combined with raw waste from TA-2 and pumped to TA-50-2, where it may be diverted to the main plant's raw or treated waste storage tanks. In cither casc, it is eventually pumped to Mortandad Canyon. If necessary, the treated TA-21-257 waste may te discharged to DP Canyon, a small branch of Los Alamos Canyon.

The TA-53 Lagoon. The lined lagoon at TA-53 does not release liquid waste to the environment.

TA-50-1, Room 116B. Precipitates from tank storage in TA-50-2 are pumped to Room 116B in TA-50-1 and concentrated to 30\%-40\% solids by a procoat-type of rotating-drum vacuum filler. Depending upon the level of alpha radioactivity in the dewatered material, it is packaged either for storage as a TRU waste or for disposal as a low-level radioactive solid waste. Dewatered TRU precipitates are packaged with dry cement powder (for moisture absorption) in 208-liter steel drums lined with a 2.25-mm-thick polyethylene container. They are sealed, have an identification tag affixed, and are transported to storage at TA-54. Low-level-activity precipitates are placed in unlined 208-liter drums, sealed, and transported to TA-54 for storage as potential mixed waste pending detailed analyses for organic constituents.

TA-50-1, Room 60. Stored precipitates from operations in TA-50-1, Room 60, are periodically pumped into cither of two drums of an enclosed double-drum umbler in the adjoining room. The drums are partially preloaded with three bags of Portand cement, a half bag of crushed exfoliated vermiculite, and about 9.5 liters of water glass. After 22 liters of the precipitate is added, the drums are sealed and umbled for $30 \mathrm{~min}$. Following removal from the tumbler, the drums are stored in an adjoining heated warehouse for a minimum of $24 \mathrm{~h}$ to permit the cement paste to set. Because all the drums contain TRU waste, identification tags are affixed and certification procedures are initiated. The drums are finally transferred to storage at TA-54, Area G, to await shipment to the Waste Isolation Pilot Plant (WIPP) at Carlsbad, NM.

TA-21-257. At TA-21-257, stored precipitates are pumped to a precoat-lype of rotating-drum vacuum filter that dewaters them to a solids content of $30 \%-40 \%$. They are packaged in 208-liter steel drums, scaled, and transported to TA-54 for storage as potential mixed waste pending detailed analyses for organic constituents.

The TA-53 Lagoon. Solids have accumulated in the TA-53 radioactive waste lagoon at a very slow rate, and it will be many years before it will be necessary to remove them. Because the lagoon is large and the volume of influent is relatively low, total evaporation occurs in the summertime, and steps are taken to keep the liner wet and anchored against high summer winds. 
References

Referral
Authorization to Discharge Under the National Pollutant Discharge Elimination System, Environmental Protextion Agency. Permil Numler NM28355, effective January 31, 1990.

Federal Water Pollution Control Act, as amended, 33 U.S.C. Soc. 1251-1387.

"Radioactive Liquid Waste," Administrative Requirement 10-1, in Environmer.. Safety, and Health Manual, Los Alamos National Laboratory Manual, Chapter I (most recent cdition).

"Radioactive Liquid Waste Collection System," Technical Bulletin 1001, in Environment, Safely, and Ilcalth Manual, Los Alamos National Laboratory Manual, Chapter 1 (most recent edition).

Waste Management Group (EM-7), 7-7391. 


\section{APPENDIX D:}

\section{Database Record Layout and Listings}




\section{FUTURE RADIOACTIVE LIQUID WASTE (RLW) STREAMS DATABASE \\ INDIVIDUAL RECORD LAYOUT}

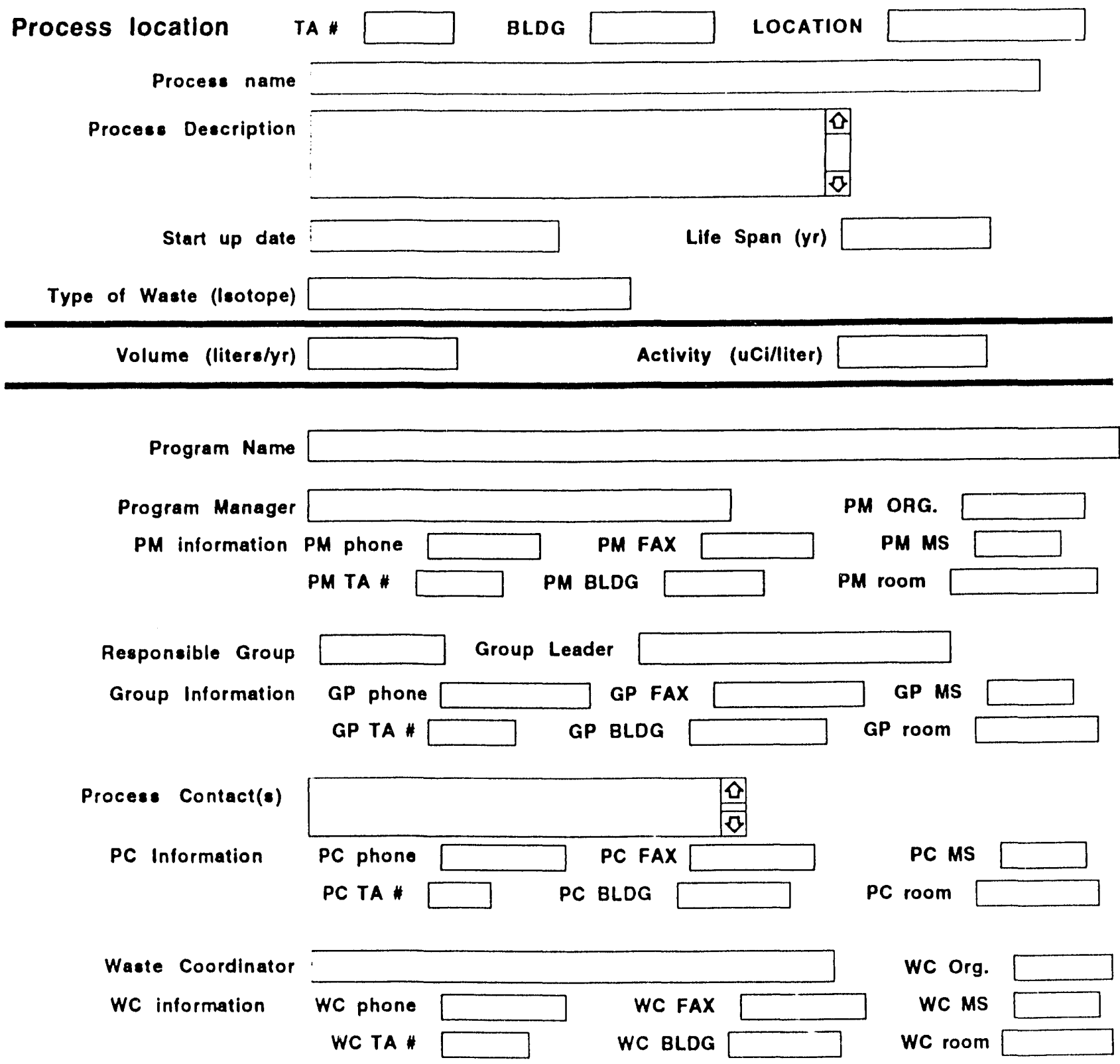


FUTURE RLW DATADATA

PROCESS, VOLUME, ACTIVITY, ETC.

\begin{tabular}{|c|c|c|c|c|}
\hline Process name & lume (1/yr) & Activity (ucliliter) & Type of Waste (lsotope) & Life Span (yr) \\
\hline ATW, Accelerator Transmutation of & "TBO" & "TBD" & Fission products, TAU, \& & 10 \\
\hline Omega West Reactor, TA2 & 550.000 & $3 \mathrm{uCn}$ & Fission products, tritium, & 50 \\
\hline Center for Material Science & 5000 & 20 nCiliter & $\mathrm{Na}-22, \mathrm{Zr}-95$ & 40 \\
\hline Health Physics Analysis Labs, TA-3 & 10 & .1 & Tritium, and TRUs & 60 \\
\hline Solid State Synthesis Electronic \& & 5 & 10 & Uranium, \& Thorium & 10 \\
\hline Moly 99 ,TA3, SM29 & 100 & 5 & Moly 99 & 10 \\
\hline Ulysses, U235 recovery \& recycle, & 20,000 & 5 & Uranium & 50 \\
\hline Hanford Tank chemistry, TA3,SM29 & 500 & .5 uCviliter & Uranium, fission products, & 10 \\
\hline Facility Generated RLW. TA3,SM29 & 900,000 & .5 & Pu239, U235, Th, Moly99, & 100 \\
\hline Condensed Matter Physics,TA3-34 & 100 & .001 & U238, Thorium & 50 \\
\hline Mechanical Fabrication, TA3, SM102 & 750,000 & .5 & U238, U235 & 50 \\
\hline U238 Processing, TA3,SM66 & 20,000 & 2 nCiliter & $U-238$ & 25 \\
\hline Weapons Engineering Tritium Facility & 30,000 & $2.5 \mathrm{uCi}$ & Tritium & 50 \\
\hline Deuterium-Tritium Fuel Cycle, TA21 & 2100 & 2 & Tritium & 10 \\
\hline Tritium Systems Tests Assembly,TSTA, & 8000 & $10 \mathrm{uCi}$ & Tritium & 10 \\
\hline Tritium Science and Fabrication Facility, & 8000 & 10 uCil & Tritium & 10 \\
\hline Actinide Organametalic chemistry, TA21 & 2000 & $.10 u C i$ & U-235, Thorium & 20 \\
\hline Uranium processing chemistry, TA21 & 2000 & $.10 \mathrm{uCi}$ & U-235, Thorium & 20 \\
\hline Technitium Chemistry R\&D, TA21 & 20 & $1000 ?$ & Technetium 99 & 20 \\
\hline Hanford Tank Safoty Issues, TA21 & 50 & .5 uCiliter & Uranium, fission products, & 10 \\
\hline ICF, AGEX II Target Fabrication, TA35 & 50 & $5 u C i$ & Tritium \& Uranium D38 & 25 \\
\hline Fission product separation, TA-48 & 200 & .5 uCilliter & Uranium, fission products, & 10 \\
\hline Medical Isotope production, TA48, & 1000 & .5 & Activated Materials & 20 \\
\hline Chemical Separation, TA48 & 1000 & .1 & fission products & 20 \\
\hline "Clean" Chemistry \& Instrumentation & 100 & $10 \mathrm{pCil}$ & Fission products & 20 \\
\hline TA-50, Health Physics Analysis Labs & 200 & .1 & Tritium, and TRUs & 60 \\
\hline Actinide Separation, TA-55, PF-4 & 200 & .5 uCiliter & Uranium, fission products, & 10 \\
\hline TA-55, Health Physics laboratory & 400 & $10 \mathrm{nCil}$ & Tritium, and TRU & 60 \\
\hline S\&S, Support of TA-55 programs & 10 & .5 & U235, and TRUs & 60 \\
\hline Plutonium Processing, facility & 200,000 & .6 & Pu 239, Pu240, other TRU & 70 \\
\hline
\end{tabular}




\section{FUTURE RLW DATABASE PROCESS AND CONTACT INFORMATION}

\section{Process name}

ATW, Accelerator

Omega West Reactor, TA2

Center for Material Science

Health Physics Analysis Labs,

Solid State Synthesis Electronic

Moly 99 ,TA3, SM29

Ulysses, U235 recovery \&

Hanford Tank chemistry,

Facility Generated RLW,

Condensed Matter

Mechanical Fabrication, TA3, U238 Processing, TA3,SM66

Weapons Engineering Tritium

Deuterium-Tritium Fuel Cycle,

Tritium Systems Tests

Tritium Science and Fabrication

Actinide Organametalic

Uranium processing chemistry,

Technitium Chemistry R\&D,

Hanford Tank Safety

ICF, AGEX || Target Fabrication,

Fission product

Medical Isotope production.

Chemical Separation, TA48

"Clean" Chemistry \&

TA-50, Health Physics Analysis

Actinide Separation, TA-55,

TA-55, Health Physics

S\&S, Support of TA-55 programs

Plutonium Processing, facility
Procese Confact(s) PC phone

Ed Arthur, EE-NSPO

Gerald Ramsey, INC-15

Aden Jackson, CM-CMS

Chris Hodge, HS-4

Kim. A. Martin, MST-5

Larry Field, MST-5

Dan Knobeloch, MST.5

Bob Villarreal, CLS-1

Theresa Cull, CLS-DO

Caleb Evans, P-10

William Hodges, WX-13

Billy Hogan, MST-6

Jay Carnes, WX-5

Richard Carlson, MST-3

Luke Bartlein, MST-3

Luke Bartlein, MST-3

Carol Burns, INC-1

Carol Burns, INC-1

Jeff Bryan, INC-1

John Watkin, INC-1

Larry Forman, MST.7

Norm Schroeder, INC-12

Sara Helmick, INC-OU

Moses Attrep, INC-12

Don Rokop, INC-6

Chris Hodge, HS-4

Gordon Jarvinen, NMT-2

Chris Hodge, HS-4

Carol Burns, INC-1

Lorenzo Trujilio, NMT-2
5.6925

7.4151

7.0239

5.6225

5.5825

5.0919

7.4653

5-7400

7-7586

5-1526

5.5665

$7-8344$

5.1228

$7-3651$

7-0434

70434

5-1765

5-1765

5-80114

5-2628

7.1846

7.0967

7-9583

$7-0088$

5-2640

5-6225

5-0822

5-6225

5.1765

$7 \cdot 2317$
Waste Coordinator WC phone

not assigned

7-4151

Miles Corrio

Aden Jackson

7-0239

Chris Hodge

5-6225

Darryl Garcia

$7-2410$

$7 \cdot 2410$

$7-2410$

7-9639

7-4731

5-1526

7-4750

7.1420

5-1228

Jay Carnes

7-2138

Dennis Hamerdinger

Dennis Hammerdinger 7-2138

Dennis Hammerdinger 7.2138

Jiri Kubicek

7-6660

Jiri Kubicek

$7-6660$

7-5046

7-6660

7-8333

5.3465

5.3465

5-3455

5-3455

5-6225

$7-2317$

5-6225

$7-2317$

7.2317
Group Leader

N/A

Eugene Peterson

Terry Lowe

Dennis Vasilik

Terry Lowe

Terry Lowe

Terry Lowe

John Phillips

Theresa Cull

Don Parkin

Robert Huggard

Tony Rollet

Robert Nolen

John Bartlit

John Bartlit

John Bartlit

Pat Unketer

Pat Unketer

Pat Unkefer

Pat Unkefer

Joseph Laia

Moses Attrep

Gene Peterson

Moses Atrep

David Curtis

Dennis Vasilik

Bill Mckurley

Dennis Vasilik

Pat Unkefer

Ronald Stafford 


\section{FUTURE RLW DATABASE LOCATION, PROCESS, VOLUME, ETC...}

\begin{tabular}{|c|c|c|c|c|c|}
\hline$\frac{\text { IA }}{0}$ & BLDG & LOCATION & $\begin{array}{l}\text { Procese name } \\
\text { ATW, Accelerator Transmutation of Wasto }\end{array}$ & $\frac{\text { Yolume (1/ver) }}{\text { "TBD" }}$ & $\frac{\text { Activity lucilliter' }}{\text { "TBD" }}$ \\
\hline 2 & 1 & & Omega West Reactor, TA2 & 550,000 & 3 uCin \\
\hline 3 & 1268 & & Center for Material Science Laboratory. TA3 & 5000 & 20 nCiniter \\
\hline 3 & 2009 & & Health Physics Analysis Labs, TA-3 & 10 & .1 \\
\hline 3 & 29, CMA & Wing 2 & Solid State Synthesis Electronic \& Magnetic & 5 & 10 \\
\hline 3 & $29, \mathrm{CMR}$ & Wing 9 & Moly 99, TA3, SM29 & 100 & 5 \\
\hline 3 & $29, \mathrm{CMR}$ & Wings $4 \& 9$ & Ulysses, U235 recovery \& recycle, TA3,SM29 & 20,000 & 5 \\
\hline 3 & 29.CMR & & Hanford Tank chemistry, TA3,SM29 & 500 & .5 uCViliter \\
\hline 3 & $29, \mathrm{CMR}$ & All & Facility Generated RLW, TA3,SM29 & 900,000 & .5 \\
\hline 3 & 34 & & Condensed Matter Physics, TA3-34 & 100 & .001 \\
\hline 3 & SM102 & main shops & Mechanical Fabrication, TA3, SM102 & 750,000 & .5 \\
\hline 3 & SM66 & Sigma & U238 Processing, TA3,SM66 & 20,000 & 2 nCiliter \\
\hline 16 & 205 & WETF & Weapons Engineering Tritium Facility (WETF), & 30,000 & 2.5 UCVIL \\
\hline 21 & 155 & TSTA & Deuterium-Tritium Fuel Cycle, TA21 & 2100 & 2 \\
\hline 21 & 209 & TSTA & Tritium Systems Tests Assembly,TSTA, TA21 & 8000 & $10 \mathrm{uCn}$ \\
\hline 21 & 209 & TSFF & Tritium Science and Fabrication Facility, TA21 & 8000 & 10 uch \\
\hline 21 & 3 & north & Actinide Organametalic chemistry, TA21 & 2000 & $.10 \mathrm{uCi}$ \\
\hline 21 & 3 & north & Uranium processing chemistry. TA21 & 2000 & $.10 \mathrm{uCi}$ \\
\hline 21 & 356 & DP SITE & Technitium Chemistry R\&D, TA21 & 20 & $1000 ?$ \\
\hline 21 & $4 N ?$ & DP east & Hanford Tank Safety Issues, TA21 & 50 & .5 uCiliter \\
\hline 35 & 213 & TFF & ICF, AGEX II Target Fabrication, TA35 & 50 & $5 \mathrm{uCi}$ \\
\hline 48 & RC-1 & Radiochem. site & Fission product separation, TA-48 & 200 & .5 uCiliter \\
\hline 48 & RC-1 & Radiochem. site & Medical Isotope production, TA48, & 1000 & .5 \\
\hline 48 & $\mathrm{RC}-1$ & Radiochem. site & Chemical Separation, TA48 & 1000 & .1 \\
\hline 48 & $\mathrm{RC}-1$ & Radiochem. site & "Cloan" Chemistry \& Instrumentation Lab, TA48 & 100 & $10 \mathrm{pCi}$ \\
\hline 50 & 1 & & TA-50, Health Physics Analysis Labs & 200 & .1 \\
\hline 55 & $P F-4$ & & Actinide Separation, TA-55, PF-4 & 200 & .5 uCilliter \\
\hline 55 & $P F-4$ & & TA-55; Health Physics laboratory & 400 & $10 \mathrm{nCin}$ \\
\hline 55 & PF-4 & & S\&S, Support of TA -55 programs & 10 & .5 \\
\hline 55 & PF4 & all & Plutonium Processing, facility generated RLW & 200,000 & .6 \\
\hline
\end{tabular}




\section{FUTURE RLW UATABASE PROGRAM MANAGER, PROCESS AND LOCATION}

\begin{tabular}{|c|c|c|c|c|c|}
\hline Pregram Manags & Process name & Process Description & IA \# & BLDG ! & Yolums llikr \\
\hline Edward D. Arthur & ATW, Accelerator & Integrated Test Facility for Accelerator & 0 & 0 & 'TBD" \\
\hline Tony Andrade & Omega West Reactor, TA2 & Nuclear reactor operations. Fission & 2 & 1 & 550,000 \\
\hline Mahion T. Wilson & Center for Material Science & Materials synthisis and characterization. & 3 & 1268 & 5000 \\
\hline Alan McMillan & Health Physics Analysis Labs, & Analysis of health physics samples, & 3 & 2009 & 10 \\
\hline Dean Peterson & Solid State Synthesis & Synthesis of electronic or magnetic & 3 & $29, \mathrm{CMH}$ & 5 \\
\hline Gene Peterson & Moly 99 ,TA3, SM29 & Project Produces Moly 99 isotope for the & 3 & 29, CMR & 100 \\
\hline Robert Behrens & Ulysses, U235 recovery \& & Modular glove box system to process & 3 & 29, CMR & 20.000 \\
\hline Kimberty Thomas & Hanford Tank chemistry, & Analytical chemistry studies of the & 3 & $29, \mathrm{CMR}$ & 500 \\
\hline Paul Cunningham & Facility Generated RLW. & Building Management information. The & 3 & $29, \mathrm{CMA}$ & 900,000 \\
\hline Don Parkin & Condensed Matter & Experimental R\&D on samples of U238 & 3 & 34 & 100 \\
\hline Harry Flaugh & Mechanical Fabrication, TA3, & Machining and Fabrication of U238 and & 3 & SM102 & 750,000 \\
\hline Allen Patterson & U238 Processing. TA3,SM66 & Depleted Uranium processing - including & 3 & SM66 & 20,000 \\
\hline Robert Nolen & Weapons Engineering Tritium & New Tritium processing Facility at TA-16 & 16 & 205 & 30,000 \\
\hline Jim Anderson & Deuterium-Tritium Fuel Cycle, & Developement of Fuelcycle for Fusion & 21 & 155 & 2100 \\
\hline John Bartlit & Tritium Systems Tests & Tritium fuel processing for fusion at TSTA & 21 & 209 & 8000 \\
\hline John Bartlit & Tritium Science and Fabrication & Production of tritiated Salts & 21 & 209 & 8000 \\
\hline Paul Cunningham & Actinide Organametalic & Researching chemical methods of & 21 & 3 & 2000 \\
\hline Paul Cunningham & Uranium processing chemistry, & Researching chemical methods of & 21 & 3 & 2000 \\
\hline Jeff Bryan, ?? & Technitium Chemistry R\&D. & Basic \& Applied Technetium Chemistry & 21 & 356 & 20 \\
\hline Kimberty Thomas & Hanford Tank Safety & Studies of Hanford Tank safety issues & 21 & $4 N ?$ & 50 \\
\hline Larry R. Foreman & ICF, AGEX $\|$ Target & Targets are fabricated then filled with & 35 & 213 & 50 \\
\hline Kimberly Thomas & Fission product & Studies of fission product separations & 48 & $\mathrm{RC}-1$ & 200 \\
\hline \multirow[t]{2}{*}{ Gene Peterson } & Medical Isotope production, & Processing of Radioactive materials to & 48 & $R C-1$ & 1000 \\
\hline & Chemical Separation, TA48 & Chemical Separation of Radioactive & 48 & $R C-1$ & 1000 \\
\hline Richard Perrin & "Clean" Chemistry \& & Weapons Radiochernical Diagnostics. & 48 & $\mathrm{RC}-1$ & 100 \\
\hline Alan McMillan & TA-50, Health Physics Analysis & Analysis of heath physics samples. & 50 & 1 & 200 \\
\hline Kimberty Thumas & Actinide Separation, TA-55, & Studies of actinide separation from the & 55 & $P F \cdot 4$ & 200 \\
\hline Alan McMillan & TA-55, Health Physics & Analysis of heatth physics samples. & 55 & $P F-4$ & 400 \\
\hline Bob Behrens & S\&S, Support of TA.55 & Actinide Chemistry processing & 55 & $P F-4$ & 10 \\
\hline Delbert Harbur & Plutonium Processing, facility & Facility acid and caustic effluent & 55 & PF4 & 200,000 \\
\hline
\end{tabular}




\section{APPENDIX E \\ Questionnaires}

INDUSTRIAL/RADIOACTIVE LIQUID WASTE QUESTIONNAIRE

(sent to Program Managers) 
In order to plan for a new Radioactive Liquid Waste Treatment Facility (RLWTF) at the Lab, a study is being conducted to forecast industrial/radioactive liquid waste generation into the mid 21 st century. The Lab's ability to continue operations generating Radioactive Liquid Waste(RLW) depends on your cooperation. Please take some time to complete this very important instrument, as it could affect the future of your program and/or projects.

\section{Please respond by $\mathrm{x}-\mathrm{x}-\mathrm{xx}$.}

Do you predict that your program will generate RLW past the year 2000?

$$
\text { q--yes q--no }
$$

If no--..-Please fill out part 1.0 below, fold in half and tape, and return by mail.

Thank you.

if yes----please fill out an entire form for each project or facility your program is expected to support and return. Thank you.

\subsection{Program name}

Program Manager/ initials

2.0 project/facility name

q existing project or facility q future project or facility(present thru 2050)

Brief Description

Approx. start date Estimated proj/facility life span(yrs.)

Contact name/ Org/Phone. 1

Waste coordinator (if assigned)

3.0 Radioactive liquid waste Characteristics:

a) Expected Volume (liters/yr.) Avg. Activity(Ci/liter)

b) Radioactive contents (please check those applicable).

$\begin{array}{ll}\text { q Fission products } & \text { q MAP Isotopes } \\ \text { q Medical Isotopes } & \text { q Transuranics } \\ \text { q Tritium } & \text { q Uranium }\end{array}$

q Other (specify)

Thank You! QUESTIONS? call Al Rey, MEE-4, 7-9088.

Please return to RLW STUDY, MS G787

or FAX to 5-1976. 


\title{
INDUSTRIAL/RADIOACTIVE LIQUID WASTE QUESTIONNAIRE
}

\author{
(sent to Building Managers)
}

In order to plan for future management of radioactive liquid waste at the Lab, a study is being conducted to forecast industrial/radioactive liquid waste generation into the mid $21 \mathrm{st}$ century. The Lab's ability to continue operations generating Radioactive Liquid

Waste(RLW) depends on your cooperation. Please take some time to complete this very important instrument, as it could affect the future of your program and/or projects. Please respond by 3-26-93 OR ASAP.

Do you predict that your facility or project is or will generate RLW?

$$
\text { q--yes q--no }
$$

If no-...-Please fill out part 1.0 below, fold in half and tape, and ieturn by mail.

Thank you.

if yes----please fill out the entire form for each project or facility and return. Thank you.

\subsection{Program name}

Line Manager/ Initials

P.ogram Manager name

\section{0 project/facility name}

existing project or facility future project or facility(present thru 2050)

Bricf Description

Approx. start date Estimated proj/facility life span(yrs.)

Contact name/ Org/Phone. 1

Waste coordinator (if assigned)

\subsection{Radioactive liquid waste Characteristics:}

a) Expected Volume (liters/yr.) Avg. Activity(Ci/liter)

b) Radioactive contents (please check those applicable).
q Fission products
q MAP Isotopes
q Medical Isotopes
q Transuranics
q Tritium
q Uranium
q Other (specify)

Thank You!

QUESTIONS? call 7-9088.

Please return to RLW STUDY, MS G787

or FAX to 5-1976. 


\section{CPM radioactive liquid waste facilities Questionnaire}

A study is being conducted to determine future quantities and types of radioactive liquid waste(RLW) streams generated by Lab projects and facilities. The purpose of the study is to provide planning information for the design of the Radioactive Liquid Waste Treatment Facility (RLWTF) which is scheduled for completion in the year 2002 with an estimated life span of 40 years.

One of the channels we are using to help determine the sources of RLW is through planned construction projects; thus the reason we have contacted you. Your cooperation will aid in acquiring more complete information about planned facilities generating RLW.

We are requesting that you check your list of construction projects and provide us information on any projects which are or will connect to the RLW lines leading to the present RLW treatment facilities at TA-50, TA-21-DP 257, and the TA-53 lagoon. Also any facility that you suspect may be used to generate RLW and plans to truck RLW to the RLWTF. Please respond by $x-x-93$.

Do you manage any projects which will connect to the RLW lines or you think may generate RLW?

$q$ yes $q$ no

-If no, Please initial item no. 1.0 below, fold in half and tape, and return.

Thank you

-if yes, Please fill out all information below for each of those projects, and return by mail to RLW STUDY, MS-G787.

(Please Print all information below)

\section{0}

CPM name

2.0

Project id. \#

Title/descrpt.

Location(TA, Bldg)

Requesting Org.

Org. contact

phone 


\section{APPENDIX F}

Memo of Estimated RLW Flows for 1990

by Facility and Group 


\author{
10. Anthony Drypolcher, EM-7, MS E517 \\ oart: August 13, 1991 \\ rnow: Jorry Buchtiolz, EM-7, E518 f) \\ umstoprecerrove: E518/7-4301 \\ srmac EM-7 91-207 \\ SUECT B88T E8TDATE OP RADIOACTIVE LIQOID WABTE VOLOLES FOR CY 1990
}

Although flow data from most major generator areas is recorded daily, no program has been written to summarize this data into an annual report. Rlch Hassman and Jeff Weinrach are now working on this problem. Therefore, the following volumes of waste are Mort Sanders' and Jerry Buchholz's best guess baset on analyzing the daily printouts.

JB:dp

TY: Mort Sanders, EM-7, MS E518

Jeff Heinrach, EM-7, MS E518

Mahelle Burns, Ex-7, MS E518

EMS-7 Files, MS E518

EM-7 Group offlce, MS E517 
Estimated Low Level Radioactive LIquid Waste Volumes by Division for CY 1990

$\begin{array}{lr}\text { Division } & \text { Volume (L } \\ \text { CLS } & 6,800,000 \\ \text { MST } & 4,400,000 \\ \text { NMT } & 4,000,000 \\ \text { INC } & 3,600,000 \\ \text { MP } & 1,400,000 \\ \text { EM } & 600,000 \\ \text { P } & 200,000 \\ \text { J } & <200,000 \\ \text { LS } & <200,000\end{array}$

Estimated TRU Radioactive Liquid Waste Volumes by Division for CY 1990

$\begin{array}{lr}\text { Dlvision } & \text { Volume (Liters) } \\ \text { MarT } & 120,000 \\ \text { EnI } & 10,000\end{array}$

Low Level Radioactive Liquid Waste Flow By Area/Division

\begin{tabular}{crl} 
TA-3-29 & Liters/Year & \multicolumn{2}{c}{ Division } \\
Wing 1 less than & 200,000 & MST \\
2 & $1,200,000$ & CLS \\
3 & $1,200,000$ & CLS MST \\
4 & 800,000 & CLS \\
5 & $2,400,000$ & CIS \\
7 & $2,400,000$ & MST \\
9 & $<200,000$ & \\
TA-3- 66 & $2,403,000$ & MST \\
TA-48 & $2,400,000$ & INC \\
TA-55 & $4,000,000$ & NMT
\end{tabular}


Th-50

$x-3-34$

TA-3-216

$T A-3-16$

$T A-43$

TA-35-2

TA-16-WITIF

$\mathbf{T A}-54$

TA-53, Tanks $68 \& 69$

Tanks $144 \& 145$

$\begin{array}{ll}600,000 & \text { EX } \\ <200,000 & P \\ <200,000 & J \\ <200,000 & \text { P } \\ <200,000 & \text { LS } \\ <200,070 & \text { NIT } \\ <200,000 & \text { MST } \\ <200,000 & \text { EYY } \\ 1,400,000 & \text { MPP } \\ 200,000 & \text { P }\end{array}$

$T-21$

MA-21-150,5 (West) $1,200,000 \quad$ IXC

T. $-21-209,152$ (East) $800,000 \quad$ MST

TRO Radioactive Ilquid Waste Volumes

T. $-55-4$

120,000

NMIT

$T A-50-69$

10,000

EY 

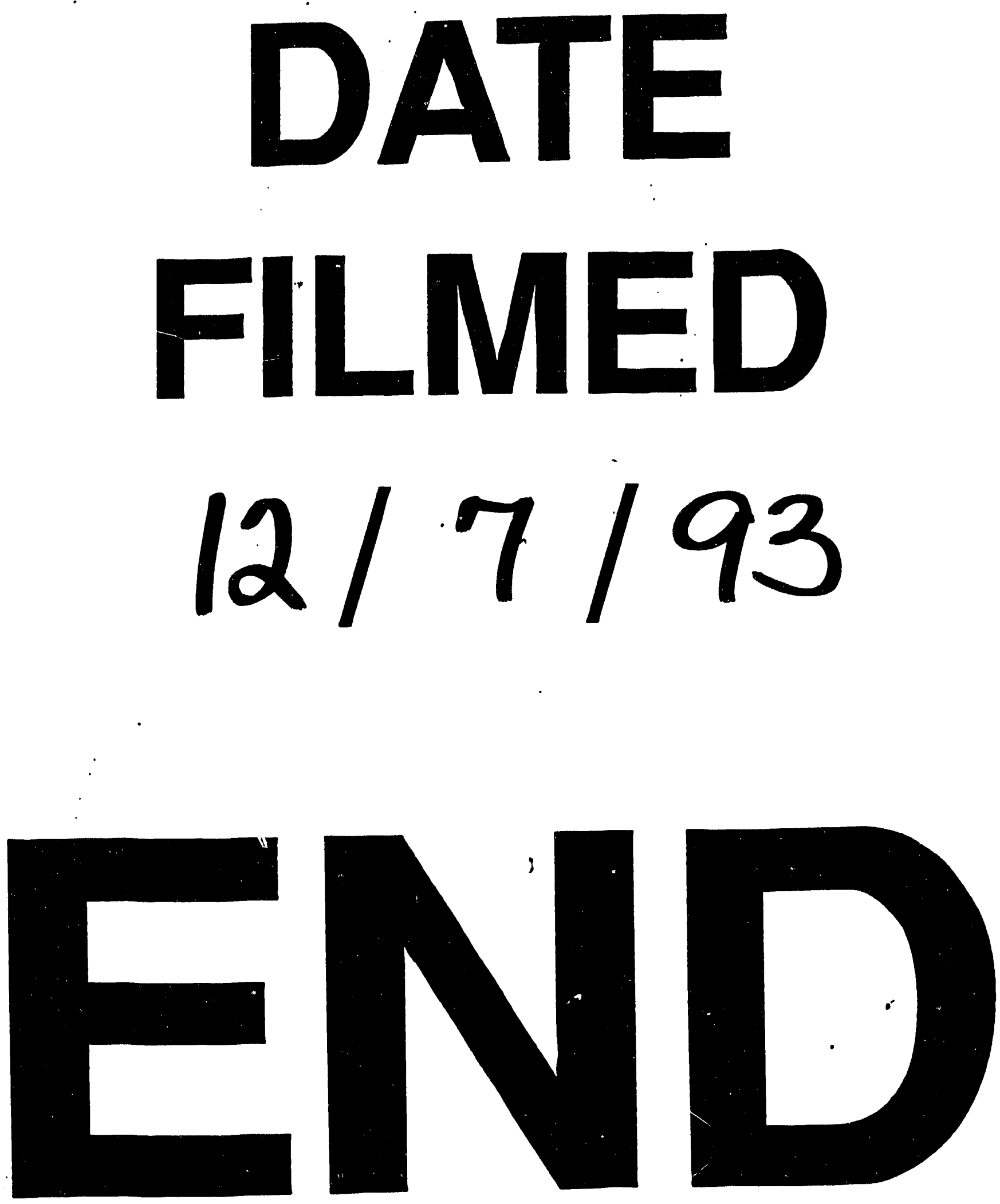


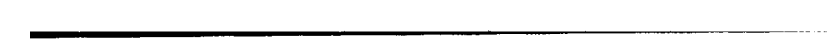

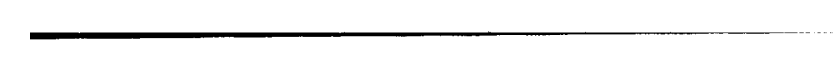

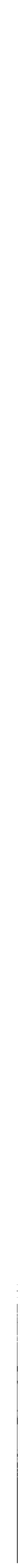

